\title{
Comparative Study of Toluene and Hexane Adsorption on Activated Carbons From Gas and Liquid Phase. Enthalpy and Isotherms
}

\author{
Diana Hernández-Monje ${ }^{1}$, Liliana Giraldo ${ }^{1}$ and Juan Carlos Moreno-Piraján ${ }^{2 *}$ \\ 'Departamento de Química, Universidad Nacional de Colombia, Bogotá, Colombia, ${ }^{2}$ Departamento de Química, \\ Universidad de los Andes, Bogotá, Colombia
}

\section{OPEN ACCESS}

Edited by:

Yacine Benguerba,

University Ferhat Abbas of

Setif, Algeria

Reviewed by:

Diana Paola Vargas,

Universidad del Tolima, Colombia

Xiangke Wang,

North China Electric Power

University, China

Suryadi Ismadji,

Universitas Katolik Widya Mandala

Surabaya, Indonesia

*Correspondence:

Juan Carlos Moreno-Piraján

jumoreno@uniandes.edu.co

Specialty section:

This article was submitted to

Sorption Technologies,

a section of the journal

Frontiers in Environmental Chemistry

Received: 16 June 2020

Accepted: 08 September 2020

Published: 21 October 2020

Citation:

Hernández-Monje D, Giraldo L and

Moreno-Piraján JC (2020)

Comparative Study of Toluene and

Hexane Adsorption on Activated

Carbons From Gas and Liquid Phase.

Enthalpy and Isotherms.

Front. Environ. Chem. 1:573402

doi: 10.3389/fenvc.2020.573402
Activated carbons with different chemical and textural properties were used to carry out the adsorption of toluene and hexane from gas phase and from liquid phase for toluene-hexane solutions where toluene was used as a solute and hexane as the solvent, complementing the process with the evaluation of the immersion enthalpy for the pure components and toluene-hexane mixtures at different molar fractions. The adsorption capacities for the gas phase were between 3.40 and $0.05 \mathrm{mmol} \mathrm{g}^{-1}$, being higher for toluene because of the $\pi-\pi$ interaction with the solid; when evaluating the liquid phase, the adsorption capacities were 0.24 and $0.74 \mathrm{mmol} \mathrm{g}^{-1}$, where the adsorption of toluene decreased compared to the gas phase because of the solute-solute, solvent-solvent, solute-solvent interaction. The immersion enthalpies for the pure solvents were between -40.87 and $-126.10 \mathrm{~J} \mathrm{~g}^{-1}$ being higher also for toluene confirming a greater interaction compared to hexane; for the mixtures, immersion enthalpy was higher than hexane enthalpies, but lower than toluene enthalpies with values between -59.79 and $-107.95 \mathrm{~J}$ $\mathrm{g}^{-1}$. It was found that there was a greater interaction between the sample with a lower content of acid groups and a greater surface area with toluene due to the high electron density of carbon and London-type as $\pi-\pi$ interactions with the aromatic compound. For mixtures, hexane decreased the adsorption capacity and interaction with respect to toluene because there was competition for adsorption sites and subsequent displacement of hexane molecules when the amount of toluene on the surface increased.

Keywords: activated carbon, liquid phase adsorption, gas phase adsorption, toluene, hexane, immersion enthalpy

\section{INTRODUCTION}

The adsorption process has been used to remove volatile organic compounds (VOCs), which are compounds that can easily pass into the vapor phase and they are used in the manufacture of several products such as waxes, varnishes, paints, detergents, cleaning products, and solvents (Cheng et al., 2016; Huang et al., 2016; Kamal et al., 2016; Mirzaei et al., 2016; Salar-García et al., 2017; Zhang et al., 2017; Zhu et al., 2020); however, they cause health damage, mainly to the central nervous system.

For the removal of VOCs, control mechanisms have emerged that can be divided into recovery methods and destruction methods; within the first ones are condensation, membrane separation, and adsorption, with respect to the latter include biodegradation, catalytic oxidation, thermal 
oxidation and plasma catalysis (Lhuissier et al., 2018; He et al., 2019; Lan et al., 2019; Tomatis et al., 2019; Guo et al., 2020; Li et al., 2020; Liu et al., 2020; Wang et al., 2020; Zhu et al., 2020). Regarding destruction methods, they generally convert VOCs into $\mathrm{CO}_{2}$ and $\mathrm{H}_{2} \mathrm{O}$, however, recovery methods are cheaper, require less energy and are less polluting ( $\mathrm{Li}$ et al., 2020; Zhu et al., 2020). Adsorption is a recovery method that is considered favorable due to its low cost and high efficiency, for which carbonaceous materials have been widely used due to their versatility, selectivity, surface area, variety of porous structure, high capacity, and fast adsorption kinetics, besides being hydrophobic solids that can be physically or chemically modified to generate greater selectivity for adsorptives of interest (Zhang et al., 2017; Zhou et al., 2017; Yang et al., 2019; Abd et al., 2020; Zhu et al., 2020).

Among the porous materials, activated carbon is used since it is a hydrophobic solid that can be physically or chemically modified to generate greater selectivity for adsorptives of interest, giving rise to interactions type $\pi-\pi$ electron donor-acceptor, $\mathrm{H}$ bonding, pore-filling, Lewis acid-base interactions or electrostatic attraction, depending of the adsorbate (Chen et al., 2020; Hu et al., 2020).

Since the volatile compounds are found in both the liquid phase and the vapor phase, it is interesting to evaluate the adsorption of these contaminants from the two phases to determine how the adsorption capacity is modified as well as some parameters that can describe the process. For this reason, it is important to fit the data from the experimental isotherms to certain models in order to characterize the adsorption, obtaining these parameters together with the appropriation of the models assumptions, can generate information on the adsorption mechanism, surface properties and the degree of affinity adsorbate-adsorbent (Foo and Hameed, 2010; Chen, 2015; Laskar and Hashisho, 2020). There are several models, however, researchers usually use the adsorption models proposed by Freundlich and Langmuir to understand the adsorption (Cheng et al., 2008). Any model fully explains the adsorption process, but allows an approach to the processes occurring inside the porous solid when an adsorptive enters to its structure.

In Langmuir's model, the surface is considered as a finite set of defined active centers that have the same probability of adsorbing a single molecule each. When the molecule reaches the surface, it collides with one of the active sites, it is adsorbed for a period of time and then it can return to the gas phase. Although this process can occur in all the adsorbed layers, Langmuir focused on the adsorption that takes place in the first layer, since it was assumed that the adsorption energy is higher for the monolayer, so more pressure is needed for formation of successive layers (Sing et al., 2014; Chen, 2015; Kecili and Hussain, 2018; Liu et al., 2019; Laskar and Hashisho, 2020). The mathematical equation related to this model is:

$$
\frac{n}{n_{m}}=\frac{b P}{1+b P}
$$

Where $\mathrm{n}\left(\mathrm{mmol} \mathrm{g}^{-1}\right)$ is the amount adsorbed per gram of the solid at an equilibrium pressure $\mathrm{P}, \mathrm{n}_{\mathrm{m}}$ is the maximum adsorption capacity in the monolayer $\left(\mathrm{mmol} \mathrm{g}^{-1}\right)$ and $\mathrm{b}\left(\mathrm{mbar}^{-1}\right)$ is the Langmuir constant which is related to the positive value of the adsorption energy (Sing et al., 2014).

Freundlich model is an empirical model that describes a nonideal and reversible adsorption, contemplating the formation of multilayer with different energies of adsorption in the active centers due to the heterogeneity of the surface, where the most energetic active sites interact first with the adsorbate, then the adsorption energy decreases exponentially until the process ends (Sing et al., 2014; Liu et al., 2019; Laskar and Hashisho, 2020). This model is applied in heterogeneous systems, especially for organic compounds or fairly similar adsorbates with activated carbon (Haghseresht and Lu, 1998; Foo and Hameed, 2010).

The mathematical relationship associated with the model is:

$$
n=K_{f} P^{1 / n}
$$

Where $\mathrm{n}\left(\mathrm{mmol} \mathrm{g}^{-1}\right)$ is the amount adsorbed per gram of the solid at an equilibrium pressure; $\mathrm{K}_{\mathrm{f}}$ is the Freundlich constant (mmol $\mathrm{g}^{-1} \mathrm{mbar}^{-1}$ ), which is associated with the adsorption capacity; $\mathrm{P}$ to the equilibrium pressure and the term $1 / \mathrm{n}$ is related to the intensity of adsorption and the heterogeneity of the surface, if this parameter is in an interval between 0 and 1 (de Sá et al., 2017; Mu and Sun, 2019).

Besides to characterize the adsorption of those two hydrocarbons from gas and liquid phase, it would be interesting to describe the system evaluating the interaction of the activated carbon with toluene and hexane at the same time changing their concentrations to see how the addition of one or another affects the energetic exchange between the adsorbates and the adsorbent. This would be possible through the calculation of a thermodynamic parameter such as immersion enthalpy $\left(\mathrm{H}_{\mathrm{i}}\right)$, which is determined by means of a technique called immersion calorimetry.

In this technique is evaluated the energy required or produced by the immersion of a liquid into a porous solid and it is quite adequate to evaluate the energetic effect of the change in the concentration of the two adsorbates since its sensitivity is high, between 10 and $100 \mathrm{~mJ}$, useful for determining interactions produced in solid-gas and solid-liquid interactions. Since this transfer of energy depends on the adsorbates and adsorbents, the determination $\mathrm{H}_{\mathrm{i}}$ also generates some added value because it can give an idea of the contribution of the change in the physicochemical properties of the solid, mainly the effect of surface chemistry on the adsorption process (Giraldo and Moreno-Piraján, 2007; Moreno-Piraján et al., 2011; Denoyel et al., 2014; Giraldo et al., 2018).

Thermodynamically, the immersion enthalpy for a microporous solid is related to the net differential heat of adsorption $\left(\mathrm{q}^{\text {nha }}\right)$ and it depends on the micropore volume filling $\left(\theta: \mathrm{V} / \mathrm{V}_{\mathrm{o}}\right)$ and the temperature $(\mathrm{T})$ (Dubinin, 1975; Stoeckli and Kraehenbuehl, 1981; Stoeckli et al., 1989):

$$
H_{i}=\int_{0}^{1} \mathrm{q}^{\mathrm{nha}}(\theta ; \mathrm{T}) \mathrm{d} \theta
$$

As the enthalpy obtained corresponds to an adsorbent-solution multicomponent type system that depends on the temperature 
and pressure $(\mathrm{P})$, this variable can be expressed as (the process is carried out at constant pressure and temperature; HernándezMonje et al., 2019a):

$$
\begin{aligned}
d H= & \left(\frac{\partial H}{\partial P}\right)_{T, n_{i}} d P+\left(\frac{\partial H}{\partial T}\right)_{P, n_{i}} d T+\left(\frac{\partial H}{\partial n_{a}}\right)_{T, P, n_{b}, n_{c}} \\
& d n_{a}+\left(\frac{\partial H}{\partial n_{b}}\right)_{T, P, n_{a}, n_{c}} d n_{b}+\left(\frac{\partial H}{\partial n_{c}}\right)_{T, P, n_{a}, n_{b}} d n_{c},
\end{aligned}
$$

According to what has been described, this research aims to evaluate the adsorption from the gas phase of toluene and hexane on activated carbons of different physicochemical characteristics and to compare the process with the adsorption from the liquid phase of toluene in the presence of hexane on these porous materials, to finally, complete the study with the energetic characterization of the immersion of the carbonaceous solids in binary toluene-hexane mixtures varying the concentration of the components. It will lead to a cross-sectional study between the adsorbent-adsorbate energy interaction and the adsorption from the liquid and gas phase of these hydrocarbons.

This will allow determining what happens with the adsorption of toluene and hexane when they are adsorbed separately from the gas phase and then when they are adsorbed from the liquid phase, making toluene the solute, and hexane the solvent; this will be interestingly complemented with the evaluation of the energetic effect of modifying the mole fractions of toluenehexane binary mixtures in the interaction with the samples of activated carbon, first evaluating the enthalpy of immersion of the pure solvent (hexane) to later add toluene to the system to change its mole fraction until toluene becomes the solvent and hexane the solute to finally determine the enthalpy of toluene as a pure solvent.

The work is novel since the adsorption of these hydrocarbons is generally studied in a single phase (mainly in the gas phase) and if it is done in the liquid phase, the solvent is water (Wang et al., 2011; Martínez De Yuso et al., 2013; Sheshdeh et al., 2014; Stofela et al., 2015), despite the fact that its solubility in this solvent is very low, instead of using an organic solvent as is done in this study, so that a comparison of the parameters obtained from the two phases is already an interesting proposal and even more so if it is complemented by the correlation with a thermodynamic parameter that can describe the energy interaction between the binary mixture and the adsorbate.

\section{MATERIALS AND METHODS}

Solids (Hernández-Monje et al., 2019b): two activated carbons. One is a commercial activated carbon (GS50, from coconut shell, Carbochem Inc., Philadelphia, USA), this was obtained by physical activation, later washed (distilled water) and dried $(373.15 \mathrm{~K}, 24 \mathrm{~h})$, it was labeled as CS; the other was obtained by subjecting a part of CS sample to a modification under thermal treatment at $1173.15 \mathrm{~K}$ with a heating ratio of $1.5 \mathrm{~K} \mathrm{~min}^{-1}$ during $9 \mathrm{~h}$ and then $1 \mathrm{~h}$ at $1173.15 \mathrm{~K}$ under $\mathrm{N}_{2}$ atmosphere at a rate of $80 \mathrm{~mL} \mathrm{~min}^{-1}$; this sample was labeled as CST.

\section{Characterization of Solids Nitrogen Adsorption Isotherms}

A sample of $80 \mathrm{mg}$ of the solid was taken and degassed at a pressure of $10^{-5} \mathrm{mbar}$ for $24 \mathrm{~h}$ at $473 \mathrm{~K}$. Then, the activated carbon was placed in the adsorption station at a temperature of $77.15 \mathrm{~K}$ and nitrogen was added in a range of relative pressures between $7^{*} 10^{-5}$ up to approximately 0.99 for the adsorption branch, also taking desorption points up to $\cong 0.3 \mathrm{p} / \mathrm{p}^{\circ}$ with an equilibrium time of $3 \mathrm{~min}$. The measurements were carried out on an Autosorb 3B, Quantachrome equipment (HernándezMonje et al., 2019b, 2020a). Then, the isotherm was used to determine surface area, pore volume, micropore volume, mesopore volume, and pore size distribution.

\section{X-Ray Diffraction}

The activated carbon was macerated until obtaining a fine powder, and it was placed on a support to measure the X-ray spectrum. This spectrum was determined in an XPERT-PRO diffractometer using $\mathrm{Cu} \mathrm{K \alpha}$ radiation source with a wavelength of $1,541 \AA$, at an approximate voltage of $45 \mathrm{kV}$ and an intensity of $40 \mathrm{~mA}$ with a range between 10 and $90^{\circ}$ (Tascón, 2007; Omri and Benzina, 2012; Lee et al., 2013; Lazzarini et al., 2016).

\section{Boehm Titrations}

Acidity content: According to what Boehm suggested, the acid groups of activated carbon are neutralized with a strong base such as sodium hydroxide. So, a sample of $100 \mathrm{mg}$ of the solid was placed in $25 \mathrm{~mL}$ of a previously standardized $0.1 \mathrm{M} \mathrm{NaOH}$ solution for 5 days under stirring at $293.15 \mathrm{~K}$, so the base reacted with all the acidic groups of the activated carbon. After that, $10 \mathrm{~mL}$ of the solution were taken and a potentiometric titration with $0.1 \mathrm{M}$ hydrochloric acid (previously standardized) was carried out in order to determine how many $\mu \mathrm{mol}$ of hydroxide remained; Thus, knowing the initial $\mu \mathrm{mol}$ and those that reacted with hydrochloric acid, it was possible to know how many $\mu \mathrm{mol}$ reacted with the carbonaceous material, taking into account the amount of sample used (Boehm, 1994; Kim and Park, 2016; Hernández-Monje et al., 2019b).

For basicity, Boehm mentioned that the basic groups in carbon were neutralized with a strong acid such as hydrochloric acid. So, the procedure that was used for acidity is performed for basicity; $\mathrm{HCl}(25 \mathrm{~mL}, 0.1 \mathrm{M}$, previously standardized) and activated carbon were put into contact to interact; then by potentiometric titration with $\mathrm{NaOH}(0.1 \mathrm{M}$, previously standardized) the remaining $\mu \mathrm{mol}$ were determined and then by difference, the $\mu \mathrm{mol}$ that interacted with the solid (Boehm, 1994; Kim and Park, 2016; Hernández-Monje et al., 2019b).

Same for lactonic and phenolic groups, since $\mathrm{NaHCO}_{3}$ neutralizes carboxylic groups and $\mathrm{Na}_{2} \mathrm{CO}_{3}$ neutralizes carboxylic and phenolic groups, so both solutions were titrated with $\mathrm{HCl}$ after interacting with carbon following the same process described above (Boehm, 1994; Kim and Park, 2016; HernándezMonje et al., 2019b).

The titrations were performed using a TitroLine alpha plus titrator from Schott Instruments. 


\section{Determination of Gas Phase Adsorption Isotherms}

The adsorbates were toluene and hexane (analytical reagents, Merck-brand) and the processes were carried out in a sortometer that was assembled in the laboratory (Hernández-Monje et al., 2019b), this equipment shown in Figure 1: the numbers that are going to be mentioned in parentheses correspond to the numbered parts in the figure.

It was made of stainless steel and it had a vacuum pump (Pfeiffer brand) (1) that allowed to reach pressures close to $3 \times$ $10^{-2} \mathrm{mbar}$; in turn, it had five valves that controlled the pressure and the pass of the adsorbate or the vacuum: venting valve (2), vacuum valve (3), adsorbate valve (4), and the valves that control the pass of the adsorbate or vacuum to the sample (5 and 6), the sortometer also had a digital sensor which showed the pressure of the system (7). There was a pressure transducer and an Extech software was used for data collection, this showed the pressure variation in terms of voltage captured with a multimeter (8) as a function of time, then with a calibration curve this voltage was converted to mbar to evaluate the isotherm.

First, $10 \mathrm{~mL}$ of the adsorbate were placed in a cell assembled to the equipment (9), then the valve (4) was opened for the passage of the adsorbate so that it passed to a tank (10) that was at $393.15 \mathrm{~K}$, so as to ensure that it was in the gas phase for the adsorption. Alternately, $1.000 \mathrm{~g}$ of activated carbon was taken in a glass cell that was assembled to the equipment (11) and it was degassed $\left(3,5,6\right.$ opened) at $180^{\circ} \mathrm{C}$ during $24 \mathrm{~h}$.

Subsequently, the desired pressure was regulated (4) to carry out the first point of the isotherm (close to $3 \times 10^{-2} \mathrm{mbar}$ ) and the sample valves were opened $(5,6)$, capturing the change of the pressure until it became constant, repeating the process until the saturation pressure was reached. The adsorption isotherms were determined at $263.15 \mathrm{~K}$ with the help of a thermostat (Cole Parmer) that kept the temperature constant (12).

\section{Determination of Liquid Phase Adsorption Isotherms}

Toluene-hexane solutions were prepared at concentrations of 20 , $40,60,100,250$, and $500 \mathrm{mg} \mathrm{L}^{-1}$ where toluene was the solute and hexane was the solvent. Then, $0.100 \mathrm{~g}$ of activated carbon were placed in a vessel; later, $10 \mathrm{~mL}$ of one of the solutions were added and left under stirring with the activated carbon at constant temperature $(273.15 \mathrm{~K})$ for the time necessary to reach equilibrium; After, the solution was filtered to remove the solid and to determine the final concentration of the solution after the adsorption process with a GC-2010 gas chromatograph that had a column VF-624ms (6\% cyanopropylphenyl, 94\% dimethylpolysiloxane) with dimensions of $0.32 \mathrm{~mm} \times 30 \mathrm{~m} \times$ $1.8 \mu \mathrm{m}$ using a flame ionization detector (FID). Helium was used as the carrier gas with a flow of $3 \mathrm{~mL} \mathrm{~min}^{-1}$. The injection volume was $1 \mu \mathrm{L}$ and the injector was at $493.15 \mathrm{~K}$ in split mode and the temperature of the oven was initially held at $318.15 \mathrm{~K}$ for $10 \mathrm{~min}$ and then the temperature started to increase at a rate of $3 \mathrm{~K} \mathrm{~min}^{-1}$ up to $473.15 \mathrm{~K}$ and it was held for $5 \mathrm{~min}$. The FID temperature was $523.15 \mathrm{~K}$ (Assadi et al., 2010; Venkatachalam and Chavare, 2010; Fu et al., 2020).

\section{Evaluation of the Immersion Enthalpy of the Activated Carbons Into the Pure Components and the Mixtures by Immersion Calorimetry}

A microcalorimeter of heat conduction Tian-Calved type was used to carry out the immersion of the solids into the liquids at 293.15 K (Moreno-Piraján et al., 2011).

For the pure components, a $10 \mathrm{~mL}$ aliquot of toluene or hexane was taken in a cell that was assembled to the calorimeter; in turn, $0.100 \mathrm{~g}$ of activated carbon were weighed in a glass cell with a fragile peak at the bottom and it was also adjusted to the calorimeter. After having the liquid and solid arranged in the equipment, the change in potential was captured as a function of time until it became constant to perform the immersion, this process consisted of breaking the fragile peak of the cell that contained the sample so that the liquid entered and the solid was immersed into the liquid, this interaction generated an increase in the potential that then decreased until a new equilibrium state was reached, so a new baseline was obtained, waiting a few minutes to confirm this equilibrium state; after, the equipment was calibrated to determine the constant of the calorimeter that together with the immersion peak allowed the calculation of the immersion enthalpy (Hernández-Monje et al., 2019a).

The same procedure was performed to the toluene-hexane mixtures.

Three mole fractions were chosen: $0.3 \mathrm{~mol}$ toluene $/ 0.7 \mathrm{~mol}$ hexane (solute: toluene/solvent: hexane), $0.5 \mathrm{~mol}$ toluene $/ 0.5 \mathrm{~mol}$ hexane (equal amounts), and $0.7 \mathrm{~mol}$ toluene $/ 0.3 \mathrm{~mol}$ hexane (solute: hexane/solvent: toluene).

\section{RESULTS AND DISCUSSION}

Regarding the physical characteristics: The $\mathrm{N}_{2}$ adsorption isotherms at $77 \mathrm{~K}$ are shown in Figure 2 (Hernández-Monje et al., 2020a). These had a similar shape and corresponded to la isotherms type according to the classification of the International Union of Pure and Applied Chemistry (IUPAC), this indicated that they were microporous solids with small external surface where the quantity adsorbed was associated to the micropore volume of the materials (Thommes et al., 2015), being higher for the CST sample than for CS; it was also evidenced that the hysteresis loops were quite closed and could be classified as type $\mathrm{H} 4$ with respect to the IUPAC classification, corresponding to micro-mesoporous carbonaceous materials (Thommes et al., 2015).

Later, the surface area was determined by means of the Brunauer-Emmett-Teller (BET) model, the total pore volume was determined at $\mathrm{P} / \mathrm{P}^{\circ} 0.99$, the micropore volume by the Dubinin-Radushkevich equation (DR), as well as the mesopore volume that was obtained by the difference between the total volume and the micropore, whose values for CS were, respectively: $851 \mathrm{~m}^{2} \mathrm{~g}^{-1}, 0.39 \mathrm{~cm}^{3} \mathrm{~g}^{-1}, 0.34 \mathrm{~cm}^{3} \mathrm{~g}^{-1}$, y 0.05 $\mathrm{cm}^{3} \mathrm{~g}^{-1}$, while for CST they had a slight increase: $934 \mathrm{~m}^{2} \mathrm{~g}^{-1}, 0.41$ $\mathrm{cm}^{3} \mathrm{~g}^{-1}, 0.38 \mathrm{~cm}^{3} \mathrm{~g}^{-1}$, y $0.03 \mathrm{~cm}^{3} \mathrm{~g}^{-1}$. This could be generated because selective removal of functional groups could give rise to access to pores that were blocked and widening of porous 


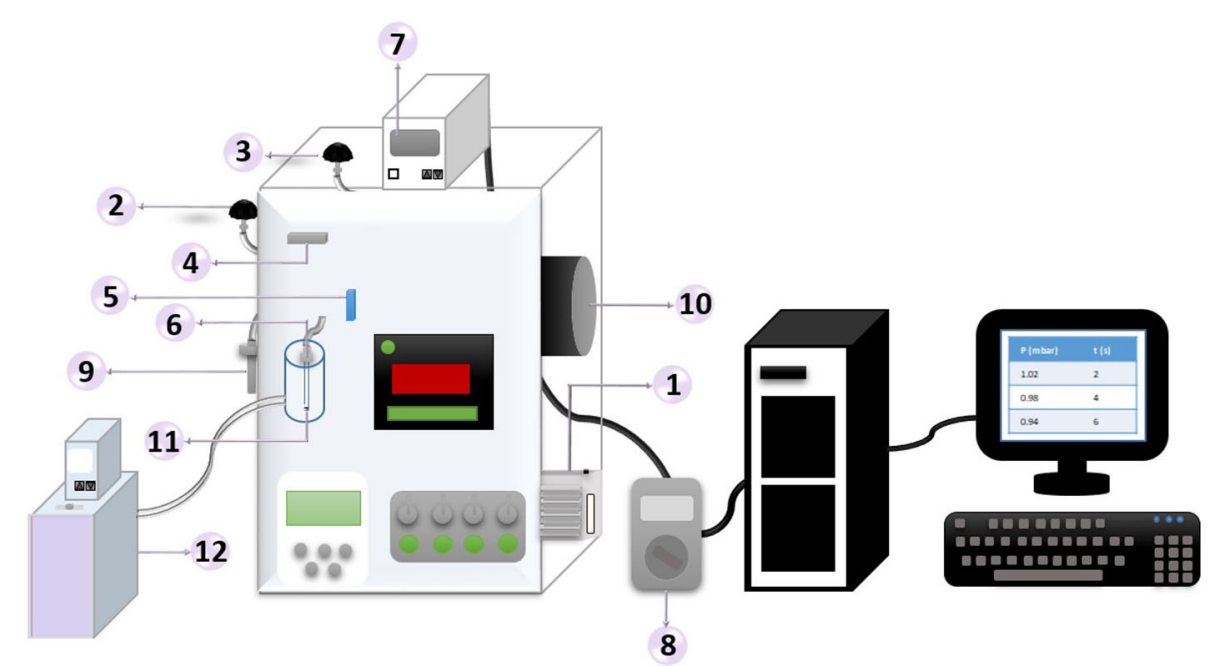

FIGURE 1 | Diagram of the sortometer used in the gas adsorption phase determinations. Adapted and modified from Hernández-Monje et al. (2020a).

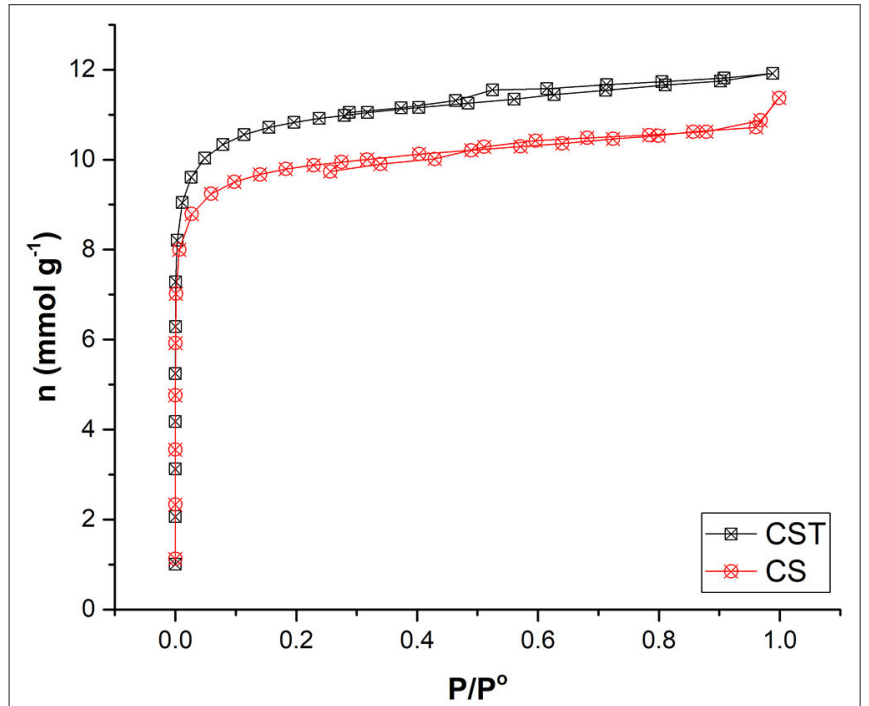

FIGURE 2 | Isotherms of gas phase $\mathrm{N}_{2}$ adsorption for CS and CST at $77.15 \mathrm{~K}$.

structures (Nguyen and Bhatia, 2012; Zhou et al., 2018). This removal was related to the thermal stability of the surface groups, since at temperatures higher than $673 \mathrm{~K}$ the carboxylic groups are removed, at $923 \mathrm{~K}$ the lactonic groups and $973 \mathrm{~K}$ the phenolics (Figueiredo et al., 1999), which are the groups that can be evaluated by Boehm titrations and whose results are shown in Figure 5 where a decrease in the content of these functional groups was indeed evidenced, which was corroborated by the pore size distribution (PSD) presented in Figure 3, since the PSD showed higher pore volumes for CST than for CS.

Figure 3 illustrates the variation of the pore volume as a function of the pore width up to $200 \AA$ and in the upper right part, there is this distribution only for micropores (up to
$20 \AA$ Å Hernández-Monje et al., 2020b), it was performed for the combined slit-cylinder pore geometry, since it was the one that presented the lowest percentage of error with respect to the fit with the experimental isotherm (CS: $0.25 \%$ and CST: $0.06 \%)$; there is shown that the highest content of pore volumes is found in sizes lower than $20 \AA$, being higher for the CST sample, which is in accordance with the textural parameters mentioned in the previous paragraph; this distribution is suitable for the adsorption of the study compounds since the molecular dimensions of hexane are $x=10.344 \AA, y=4.536 \AA$, $z=4.014$ $\AA$ and of toluene are: $x=6.625 \AA, y=4.012 \AA, z=8.252 \AA$ (Webster et al., 1998).

To complement the information regarding the change in the structure of the activated carbon due to thermal modification, the XRD determinations corresponding to the CS and CST samples are shown in Figure 4. There were shown the bands obtained between 20 and $30^{\circ}$ corresponding to the reflection of graphite in the mentioned plane, which were similar for the evaluated samples and according to references they were related to the stacked structure of the aromatic layers (Rodríguez et al., 2007; Liu et al., 2010); these bands showed widening, which indicated a low degree of ordering of the material (Tascón, 2007). On the other hand, it could be seen that the band became a little sharper close to $27^{\circ}$ for the CST sample, which indicated that the thermal modification could slightly favor the increase in the crystalline structure due to the increase in temperature, since it was mentioned in the literature that thermal treatment could increase the ordering of the structure due to the fact that high temperatures favored the grouping of sheets of polyaromatic compounds arranged in parallel by means of van der Waals type forces (Tascón, 2007; Biniak et al., 2010).

On the other hand, regarding the changes in surface chemistry, Figure 5 shows the total acidity and basicity content for each sample (Figure 5A) and the content of phenolic, carboxylic and lactonic groups (Figure 5B) based on the Boehm tirations. In the CST sample, the heat treatment substantially 


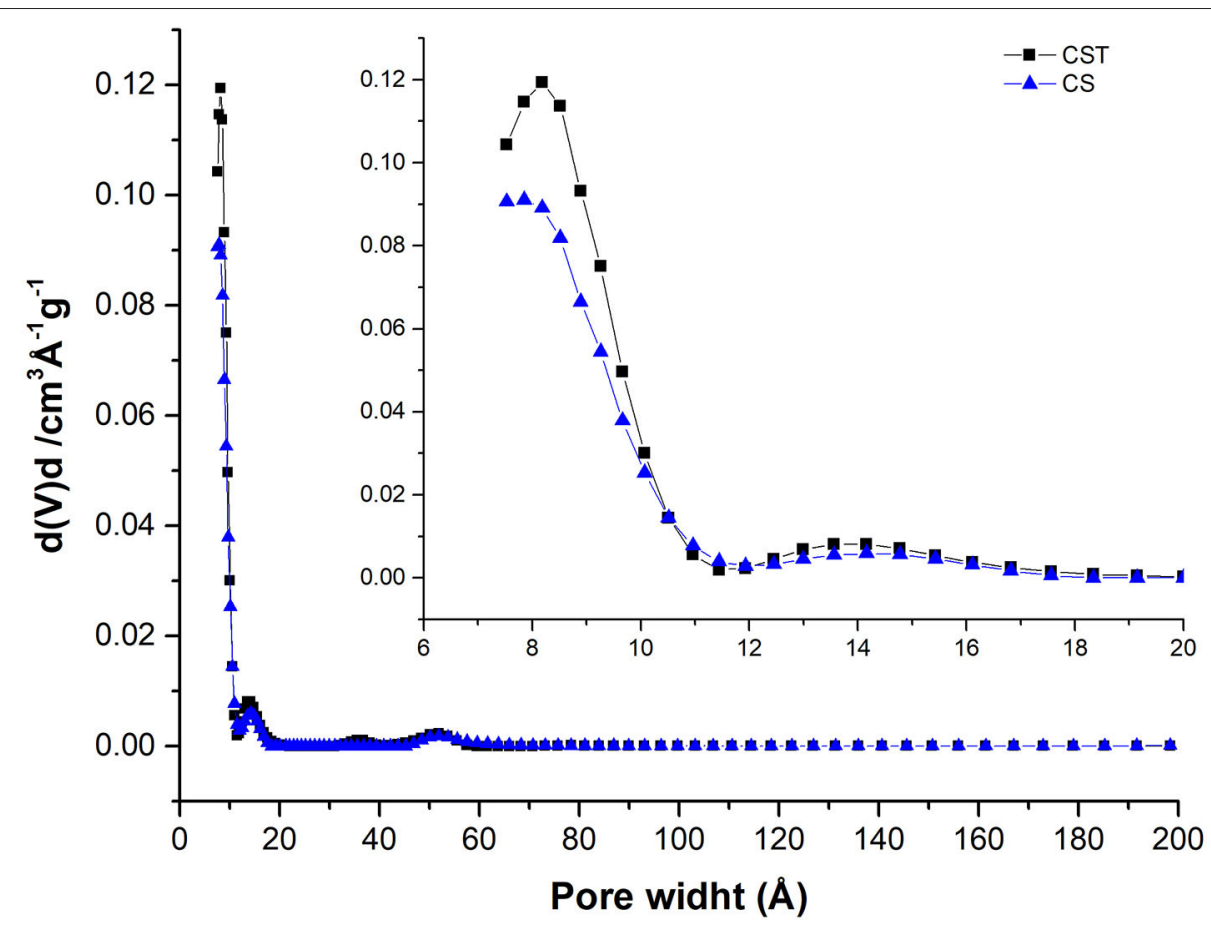

FIGURE 3 | Variation of the pore volume as a function of the pore width obtained by the QSDFT model (slit-cylinder pore geometry) for the activated carbon samples with a magnification window in the area of the micropores (upper right).

decreased the content of acid groups almost five times its magnitude and tripled the content of basic groups. In turn, subjecting the starting sample to $1173.15 \mathrm{~K}$ removed practically all the carboxylic groups and reduced to a third the concentration of phenolic and lactonic groups, where the phenolic > lactonic groups. This occurred because the thermal stability of these groups was $<1173.15 \mathrm{~K}$, so that they could be removed as the temperature increases, since the thermal stability is of the order: carboxylic groups $(373-673 \mathrm{~K})<$ lactonic $(463-923 \mathrm{~K})$ $<$ phenolic (873-973 K) (Figueiredo et al., 1999), which is why the carboxylic groups were not detected after treatment at this temperature and phenolic groups were found in a higher proportion than lactonic ones.

According to the above, the starting sample showed high heterogeneity in the content of the surface groups with a predominance of acid character and a smaller surface area compared to CST, on the other hand, the sample modified with temperature had a greater surface area and a lower concentration of surface groups, practically null content of carboxylic groups and predominance of basic character.

Figure 6 contains the isotherms from the toluene and hexane gas phase on the CS and CST samples.

With respect to adsorbates, toluene was adsorbed in a greater proportion in both samples compared to hexane; with respect to samples, CST adsorbed a greater amount of contaminant than CS. For the toluene-CST system most of the adsorbed amount occurred at low relative pressures, as in the hexaneCS system, with the difference that this last isotherm reached a plateau at very low relative pressures $(<0.2)$, making the

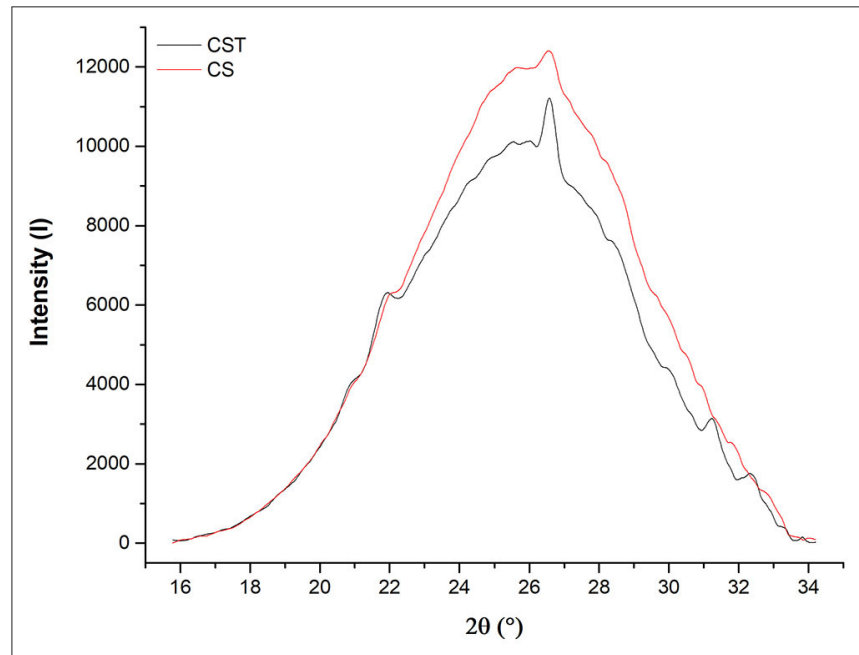

FIGURE 4 | Diffractograms for CST and CS samples.

amount adsorbed very low too, so much so that the most efficient adsorption system was with the heat-treated sample used as an adsorbent and toluene as the adsorbate, while the least amount adsorbed occurred when the starting sample was used for the aliphatic molecule. Regarding the systems of intermediate adsorbed amounts (toluene-CS and hexane CST), most of the amount wasn't adsorbed at low relative pressures, but the concentration of the hydrocarbon on the solid increased at medium relative pressures. 

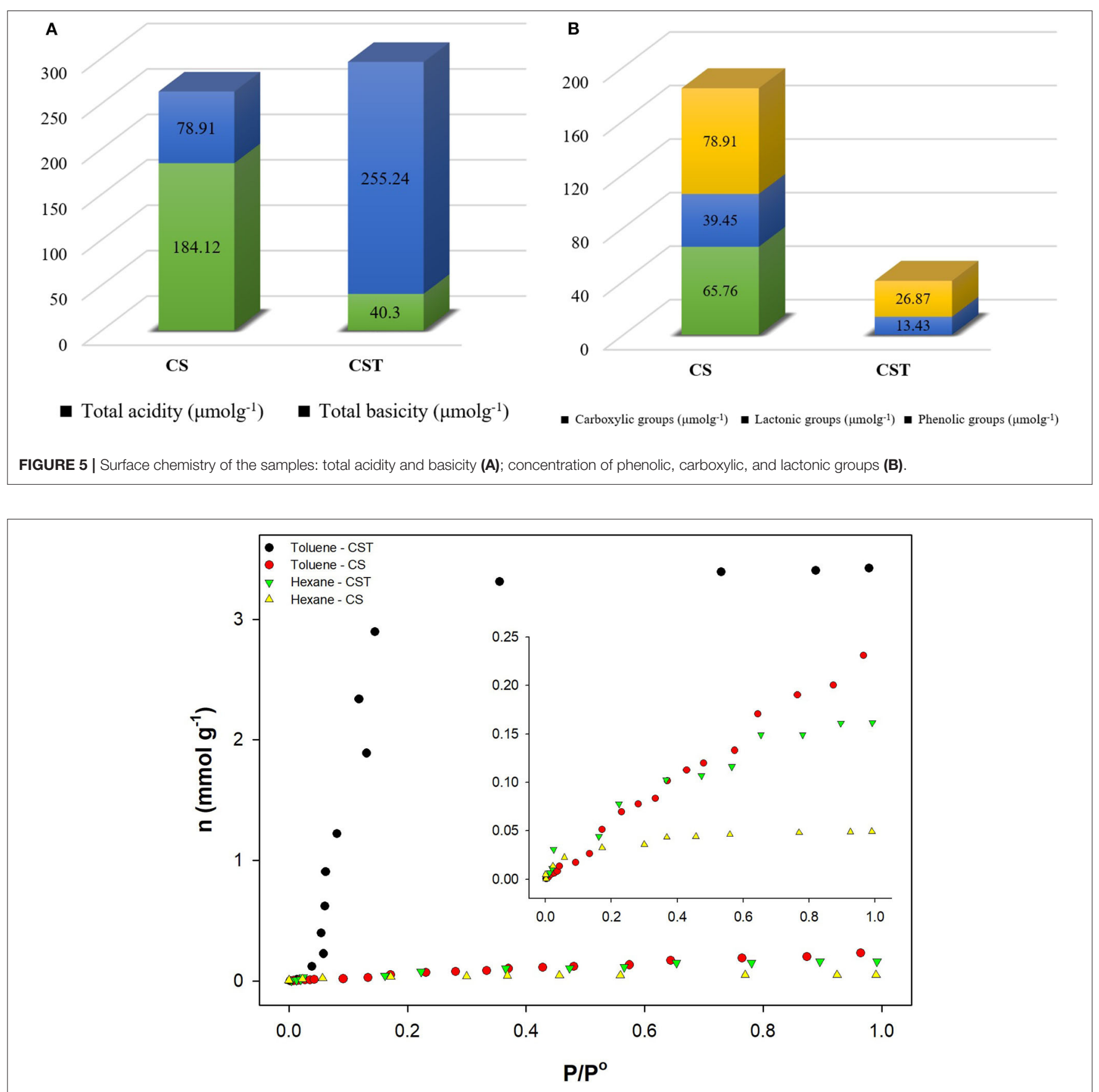

FIGURE 6 | Gas phase adsorption isotherms of toluene and hexane on CS and CST.

The aforementioned is complemented by the research carried out by Zhou et al. (2019) and Hossein Tehrani et al. (2020), who through DFT calculations suggested that the interaction between toluene and the carbonaceous material was related to the fact that both contained aromatic structures, which led to $\pi-\pi$ stacking interaction between them, increasing dispersion forces among the adsorbate and the adsorbent, even more when the $\mathrm{CH}_{3}$ group increased the density of $\pi$ electrons in the ring and it provided a $\mathrm{CH}-\pi$ type interaction (Thongsai et al., 2019), giving rise to a physisorption process where toluene showed a flat orientation parallel to the solid with a distance of $3.211 \AA$ between the hydrogen of the methyl and the carbon structure (Zhou et al., 2019).

While for a study with respect to hexane (Thongsai et al., 2019) it was found that this molecule was aligned in a parallel way to carbon with seven hydrogen atoms pointing to the surface at a distance of $3.69 \AA$ showing interactions $\mathrm{CH}-\pi$ type; this helped to explain why the amount of $\mathrm{C}_{6} \mathrm{H}_{14}$ adsorbed was lower 


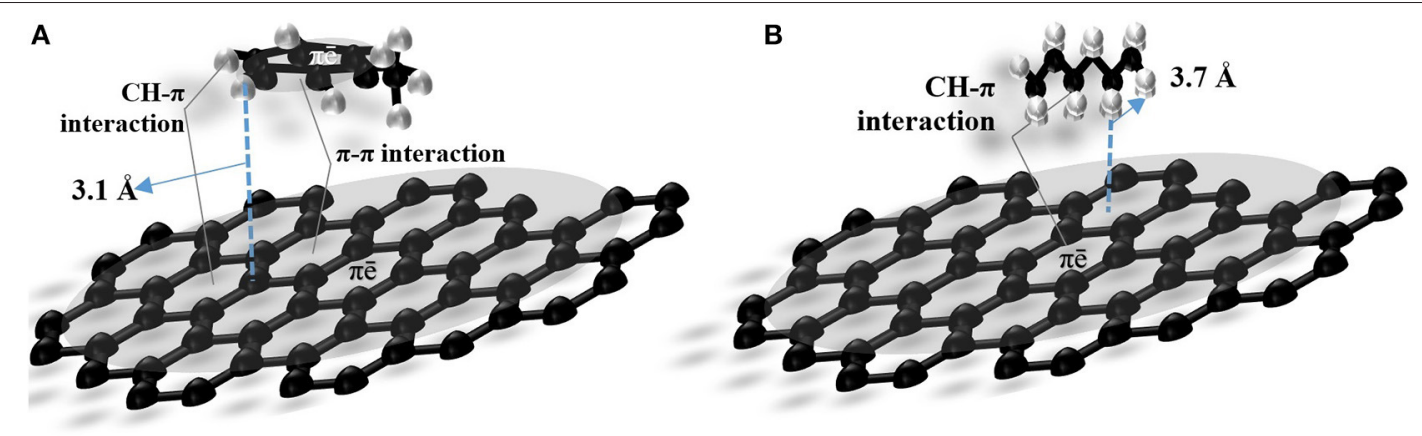

FIGURE 7 | Top view of the possible interaction between an activated carbon and toluene (A: left image) and hexane (B: right image). Adapted and modified from Zhou et al. (2019) and Thongsai et al. (2019).

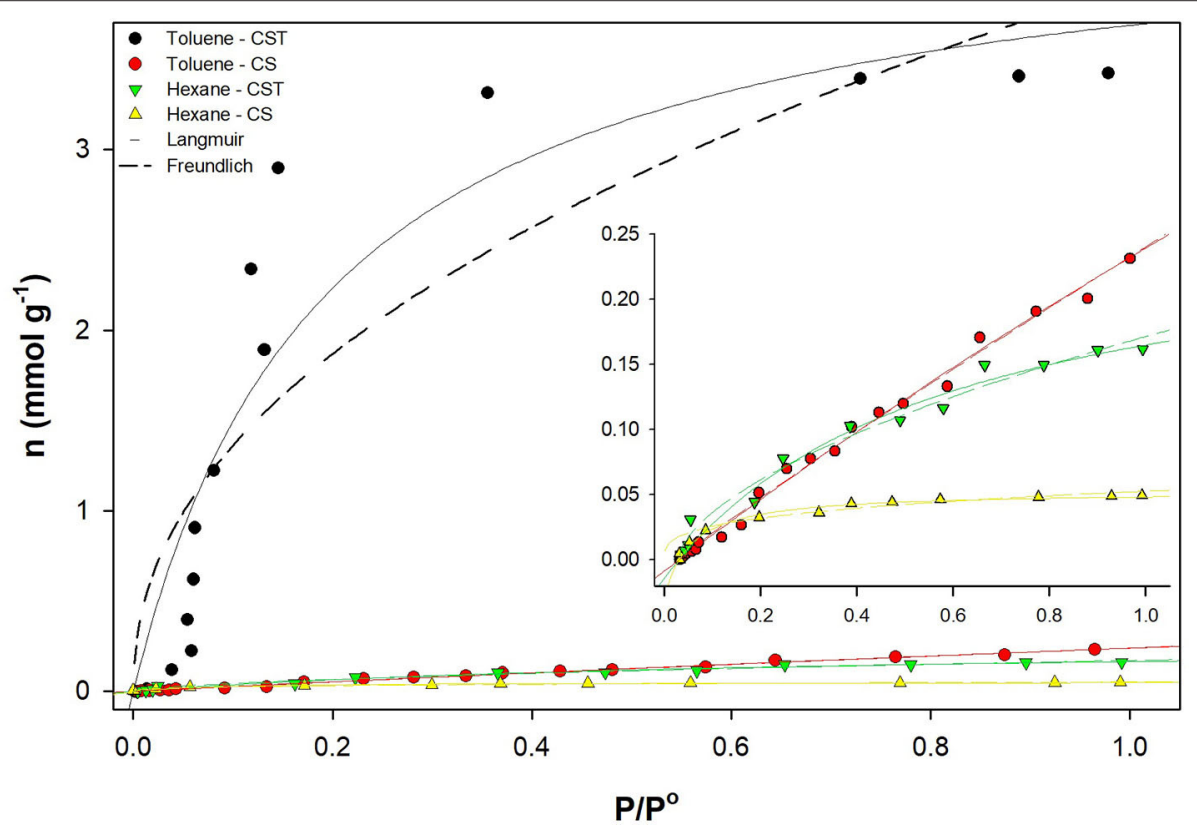

FIGURE 8 | Gas phase adsorption isotherms of toluene and hexane on CS and CST adjusted to the Langmuir and Freundlich models.

compared to toluene: its molecular arrangement and because it only showed $\mathrm{CH}-\pi$ interaction; while toluene not only gave rise to $\mathrm{CH}-\pi$ interactions but also $\pi-\pi$ interactions. According to the references mentioned above and what was discussed, a top view of the possible interaction between toluene and hexane is shown in Figure 7; black spheres are for $\mathrm{C}$ atoms and white for $\mathrm{H}$, the gray shaded area represents the $\pi$-electron density of the toluene and the basal plane, and the value in angstroms corresponds to the distance between the hydrogen atom of the molecule and the surface.

To characterize the adsorption process, these isotherms were adjusted to Langmuir and Freundlich models (Figure 8) and the results of this characterization are in Table $\mathbf{1}$.

According to the values obtained by adjusting to the models, toluene was adsorbed in a greater proportion than hexane. With respect to the Langmuir model, $\mathrm{n}_{\mathrm{m}}$ for toluene/CST (4.524 mmol $\left.\mathrm{g}^{-1}\right)>$ toluene/CS $\left(2.023 \mathrm{mmol} \mathrm{g} \mathrm{g}^{-1}\right)>$ hexane/CST $(0.269$ mmol $\left.\mathrm{g}^{-1}\right)>$ hexane/CS $\left(0.052 \mathrm{mmol} \mathrm{g}^{-1}\right)$ where for the first adsorbate, the amount of toluene adsorbed decreased by $55 \%$ if it was adsorbed on the starting sample instead of on CST; on the other hand, the amount of hexane adsorbed on CST decreased to about a quarter if it was adsorbed on CS. This same correlation was corroborated with $\mathrm{K}_{\mathrm{f}}$, the parameter of Freundlich model associated to the adsorbed quantity, which followed the next order: $\mathrm{K}_{\mathrm{f}}$ for toluene / CST (4.580 $\left.\mathrm{mmol} \mathrm{g}^{-1} \mathrm{mbar}^{-1}\right)>$ toluene/CS (0.241 mmol g $\left.\mathrm{g}^{-1} \mathrm{mbar}^{-1}\right)>$ hexane/CST (0.172 mmol g ${ }^{-1}$ mbar $\left.^{-1}\right)>$ hexane/CS $\left(0.053 \mathrm{mmol} \mathrm{g}^{-1} \mathrm{mbar}^{-1}\right)$, in turn, parameter $1 / \mathrm{n}$ is $<1$ for all systems, indicating that these are heterogeneous samples.

It was also seen that toluene-CST and hexane-CS systems showed a better fit to the Langmuir model. This indicates that in both systems the adsorbate starts to be adsorbed until it forms 
TABLE 1 | Parameters obtained from the fit to the Langmuir and Freundlich models for the gas phase adsorption isotherms of toluene and hexane on CS and CST.

\begin{tabular}{|c|c|c|c|c|c|c|}
\hline \multirow{2}{*}{$\begin{array}{l}\text { Adsorbate- } \\
\text { adsorbent }\end{array}$} & \multicolumn{3}{|c|}{ Langmuir } & \multicolumn{3}{|c|}{ Freundlich } \\
\hline & $\begin{array}{c}\mathrm{n}_{\mathrm{m}} \\
\left(\mathrm{mmol} \mathrm{g}^{-1}\right)\end{array}$ & $\begin{array}{c}\mathrm{b} \\
\left(\mathrm{mbar}^{-1}\right)\end{array}$ & $R^{2}$ & $1 / n$ & $\begin{array}{c}\mathrm{K}_{\mathrm{f}} \\
\left(\mathrm{mmol} \mathrm{g}^{-1} \mathrm{mbar}^{-1}\right)\end{array}$ & $R^{2}$ \\
\hline Toluene-CST & 4.524 & 4.580 & 0.895 & 0.458 & 3.908 & 0.763 \\
\hline Toluene-CS & 2.023 & 0.134 & 0.995 & 0.930 & 0.241 & 0.995 \\
\hline Hexane-CST & 0.269 & 1.596 & 0.981 & 0.589 & 0.172 & 0.982 \\
\hline Hexane-CS & 0.052 & 11.448 & 0.982 & 0.309 & 0.053 & 0.967 \\
\hline
\end{tabular}

a monolayer, due to two different behaviors: in the tolueneCST system, due to the high basicity and a high percentage of microporosity, toluene can be arranged in the micropores of the activated carbon, generating $\pi-\pi$-type interactions (Goto et al., 2015), having sites with which to generate van der Waalstype interactions and the sufficient amount of micropores to be arranged in a monolayer until reaching the saturation pressure, retaining a high amount of adsorbate.

While in the case of hexane-CS, this sample is the one that presents the greatest heterogeneity with respect to surface chemistry and the lowest values of surface area and micropore volume, due to this and added to the fact that hexane tends to be arranged as an elongated cylinder (Wang et al., 2015), the formation of a monolayer can be reached at low relative pressures with a much lower amount of this adsorbate compared to toluene, which is evidenced in the adsorption isotherms since the amount adsorbed in the monolayer for toluene is $4.524 \mathrm{mmol} \mathrm{g}^{-1}$, while for hexane is $0.052 \mathrm{mmol} \mathrm{g}^{-1}$.

For the other systems, toluene-CS and hexane-CST that had a similar adjustment for Freundlich and Langmuir model could occur that, for the first case, due to toluene molecules can be stacked (Živković et al., 2019) and CS sample has a high content of phenolic groups, the interaction of the $\pi$ electrons of these functional groups of activated carbon with those of $\mathrm{C}_{7} \mathrm{H}_{8}$ can be increased, as well as $\mathrm{CH}-\pi$ interactions with the aromatic part (Nishio et al., 2009; Živković et al., 2019), so that the adsorbate molecules can stack on the phenolic groups, causing that the amount adsorbed increases throughout all the pressure range. While in the case of hexane with the CST sample, as there is a greater volume of pores, mainly $<10 \AA$, there is a greater adsorbed amount of this hydrocarbon with respect to CS, leading to a monolayer formation at much higher pressures (close to $\left.0.6 \mathrm{P} / \mathrm{P}^{\circ}\right)$.

On the other hand, for $n_{m}$ and $K_{f}$ the effect of both the adsorbent and the adsorbate can be seen, regarding the influence of the adsorbent, the increase in the surface area and the low content of surface groups increased the interaction with hydrocarbons; with respect to the adsorbate, the dimensions and orientation of the molecule for its entry into the porous structure, as well as the presence of delocalized $\pi$ electrons could favor the adsorption and the interaction with surface groups, since the molecular dimensions of toluene were: $x=6.625 \AA, y=4.012$, $z=8.252 \AA$, while those for hexane were: $x=10.344 \AA$, $y=$ 4.536, $z=4.014 \AA$ (Webster et al., 1998), so that in the $x$ and $y$ dimensions hexane had a higher molecular size, so if the molecule

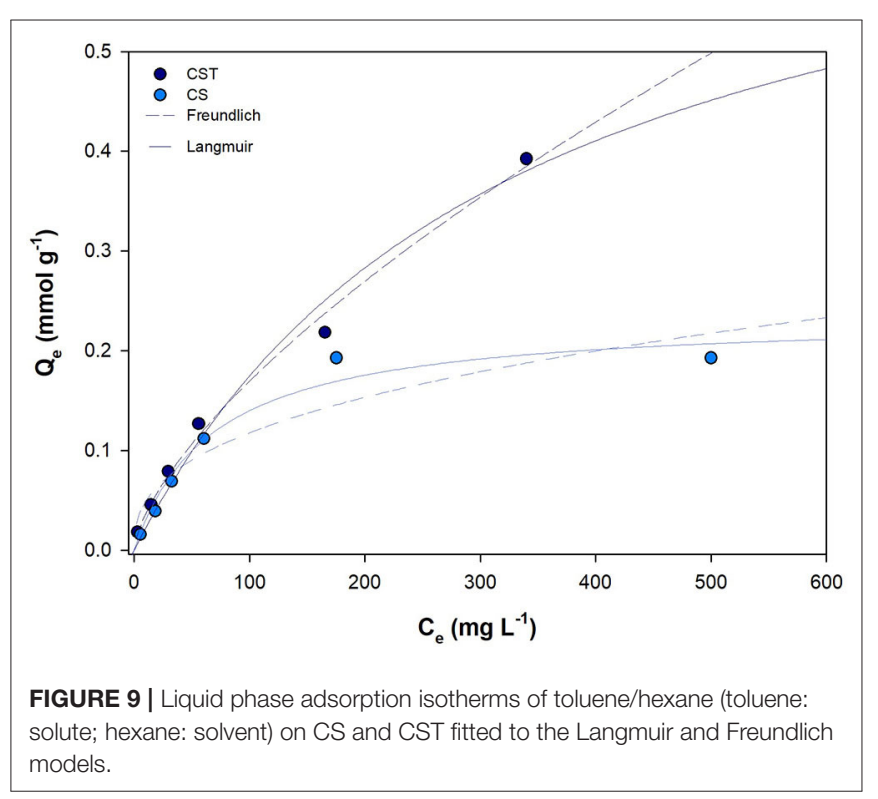

was oriented in this way would have greater restrictions to enter the porous structure with respect to toluene, which would make fewer molecules enter the surface of the solid, generating lower values of the quantity adsorbed.

After evaluating adsorption from the gas phase, Figure 9 shows the adsorption isotherms from the liquid phase of toluene / hexane (toluene: solute; hexane: solvent) on CS and CST fitted to the Langmuir and Freundlich models, to see the effect of adding a solvent to toluene and carrying out the process in the liquid phase, as well as the influence of the sample used in the adsorption process. Likewise, the results of the values obtained are shown in Table 2.

The effect of the samples remained the same, which showed that the sample subjected to heat treatment at $1173.15 \mathrm{~K}$ adsorbed more of the substances of interest, regardless of whether the phase was liquid or gas, or if another adsorbate was added to the system. For the liquid phase, the adsorbed amount tripled if the CST sample was used instead of CS and it could also be seen that when hexane was used as a solvent for toluene, the adsorbed amount of toluene decreased to one fifth for the sample CST and it was reduced practically eight times for the CS sample. What might be happening was that by affinity, size and orientation, as mentioned above, initially toluene was adsorbed in 
a greater proportion while the filling of the micropores occurred, but then part of the adsorbed toluene was displaced by hexane, which made the amount adsorbed less for the liquid phase than for the gas phase, since for the liquid phase toluene competed with hexane for adsorption sites, these adsorption sites were heterogeneous according to what was obtained by the Freundlich model since the parameter $1 / \mathrm{n}$ is still less than one, as in the gas phase (Golomeova and Zendelska, 2016; de Sá et al., 2017; Mu and Sun, 2019).

There was also an effect of the structure and the size of the porosity in the adsorption process, since according to the pore size distribution the solid showed a porosity of combined slitcylinder geometry, which is quite suitable for adsorbates since toluene has a planar arrangement and hexane an elongated cylinder shape; so, what could happen in the adsorption process was that toluene, due to its molecular arrangement, could be more easily located in a slit pore while hexane in cylinder-type ones and if the pores were smaller than $10 \AA$ (as is the case for most of the pore volume according to PSD) both adsorbates would be oriented parallel to the surface because the pores are too small to maintain another orientation (Hofmann et al., 2012; Klomkliang et al., 2012); on the other hand, when the pore size was close to $10 \AA$, as suggested by Diao et al. (2019), toluene could be oriented perpendicular to the surface and if the pore size was $>12 \AA$, two layers of adsorbate molecules could be generated, both with parallel orientation; while when the pore size had sizes equal to or $>14 \AA$, it was mentioned that two layers of toluene molecules would be generated, one with a parallel orientation and the other with a perpendicular orientation (Diao et al., 2019); regarding the cylindrical pores, it was proposed that with a linear configuration of the adsorbate in small pores, a high positional ordering could be achieved inside the cylinder, where it was shown a greater adsorption for ring-like compounds than for linear ones (Cárdenas and Müller, 2019).

As the parameter $1 / \mathrm{n}$ is also associated with the intensity of the interaction between the adsorbent and the adsorbate (de Sá et al., 2017; Mu and Sun, 2019), Figure 10 shows the relationship between $n_{m}$ and $1 / n$ obtained for the liquid and gas phase and the trend of a directly proportional relationship between both parameters was seen, this occurred because the adsorption on the micropores was associated with their potential of adsorption, which is high due to the superposition of the fields existing in those pores (Dubinin, 1980) and by increasing the amount adsorbed increased the number of molecules that interacted with the microporous structure and therefore with these adsorption potentials, which made higher the intensity of the adsorbentadsorbate interaction.

After evaluating the adsorption from liquid and gas phase, the immersion enthalpies of binary mixtures of toluene-hexane were determined, where it started from hexane as a pure solvent and $\Delta \mathrm{H}_{\mathrm{i}(\mathrm{h})}$ was evaluated, then 0.3 moles of toluene were taken

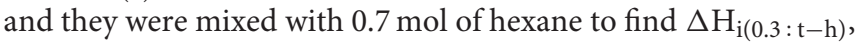
later the immersion enthalpy of the mixture of $0.5 \mathrm{~mol}$ of toluene and $0.5 \mathrm{~mol}$ of hexane $\Delta \mathrm{H}_{\mathrm{i}(0.5: \mathrm{t}-\mathrm{h})}$ was determined, after the immersion enthalpy of the mixture of $0.7 \mathrm{~mol}$ of toluene with $0.3 \mathrm{~mol}$ of hexane $\Delta \mathrm{H}_{\mathrm{i}(0.7: \mathrm{t}-\mathrm{h})}$ and finally the immersion of toluene was carried out as a pure solvent to find $\Delta \mathrm{H}_{\mathrm{i}(\mathrm{t})}$; the determinations were made on both samples, CS and CST.

The results are found in Table 3 and the relationship between the molar fractions of toluene and $\Delta \mathrm{H}_{\mathrm{i}}$ is shown in Figure 11. The calorimetric determinations were carried out in triplicate with standard deviation values between 0.68 and $1.91 \mathrm{Jg}^{-1}$.

Figure 11 corresponds to the immersion enthalpies of pure solvents or toluene-hexane mixtures in function of the molar fraction of toluene in the mixture. This showed the region of the mixtures (center of the figure, dark green square) and the edges where the pure solvents were. For the pure solvents, the intensity of the interaction was greater with toluene than hexane (it increased 2.5 times for CS and it doubled for CST); this occurred because both showed London dispersion interactions, which were originated between an adjacent pair of atoms or molecules when they were in close proximity and they were attractive forces between non-polar organic molecules (Mantri et al., 2017), such as hexane and toluene; but toluene, in addition to causing this type of forces, generated $\pi-\pi$ interactions between its aromatic ring and the delocalized $\pi$ electrons of the graphene layers of the activated carbon (Rehman et al., 2019; Rubahamya et al., 2019). Besides, the methyl group of toluene is an electron-donating group which also contributed to increasing the electronic density of the ring (Bazzini and Wermuth, 2015) and then, the interaction with the $\pi \bar{e}$ of the graphitic surface of the porous solid.

As for the mixtures, the above was confirmed, since by adding $0.3 \mathrm{~mol}$ of toluene to hexane the enthalpy increased considerably (it doubled for CS and increased 1.5 times for CST), this increase was due to the fact that by immersing the solids in the two compounds, by orientation (Webster et al., 1998) and affinity (Rehman et al., 2019; Rubahamya et al., 2019) there was probably a higher entry of toluene molecules than hexane into the porous structure and since there were more interactions with $\mathrm{C}_{7} \mathrm{H}_{8}$ [London forces (Mantri et al., 2017), $\pi$ $\pi$ interactions (Rehman et al., 2019; Rubahamya et al., 2019)] than with $\mathrm{C}_{6} \mathrm{H}_{14}$ (London forces; Mantri et al., 2017) more energy was released in the process becoming more exothermic; however, as the concentration of toluene increased, the enthalpy of immersion decreased, this inversely proportional relationship occurred because as the amount of toluene increased, there was greater displacement of hexane molecules, which implied a higher energy consumption since this process was endothermic (Unnikrishnan and Srinivas, 2016), which is reflected in a decrease in the enthalpy of the mixture when it was compared to $\Delta \mathrm{H}_{\mathrm{i}}$ for pure toluene.

Regarding to the samples, electron density of the adsorbent depended on its type of surface chemistry: electron withdrawing groups (like oxygen surface groups) reduced the adsorptive potential of the material whereas donating functional groups favored the electron density and then the adsorptive potential of the carbonaceous solid (Montes-Morán et al., 2012; Rubahamya et al., 2019). This is why enthalpies for CS were lower than for CST, since CS contained higher concentration of acidic oxygen groups, which reduced the electron density and the potential adsorptive of activated carbon, as well as the adsorption 
TABLE 2 | Parameters obtained from the fit to the Langmuir and Freundlich models for the liquid phase adsorption isotherms of toluene/hexane on CS and CST.

\begin{tabular}{|c|c|c|c|c|c|c|}
\hline $\begin{array}{l}\text { Adsorbates- } \\
\text { adsorbent }\end{array}$ & \multicolumn{3}{|c|}{ Langmuir } & \multicolumn{3}{|c|}{ Freundlich } \\
\hline Toluene/Hexane-CST & 0.742 & 0.003 & 0.978 & 0.6699 & 0.01 & 0.994 \\
\hline Toluene/Hexane-CS & 0.238 & 0.015 & 0.969 & 0.3817 & 0.02 & 0.858 \\
\hline
\end{tabular}

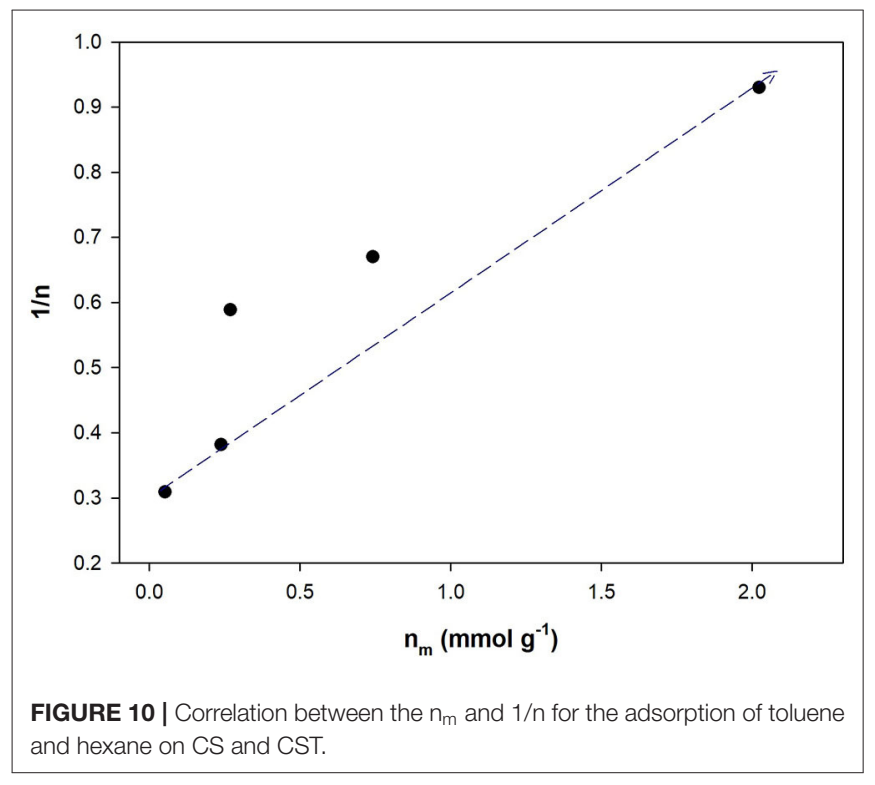

TABLE 3 | Immersion enthalpies of CS and CST into hexane, toluene, and mixtures toluene-hexane.

\begin{tabular}{lcc}
\hline Solvent or mixture & \multicolumn{2}{c}{$\boldsymbol{\Delta} \mathbf{H}_{\mathbf{i}}\left(\mathbf{J ~ g}^{-\mathbf{1}} \mathbf{)}\right.$} \\
\cline { 2 - 3 } & $\mathbf{C S}$ & $\mathbf{C S T}$ \\
\hline Hexane & -40.87 & -66.14 \\
$0.3 \mathrm{~mol}$ Toluene/0.7 mol Hexane (0.3: t-h) & -76.60 & -104.05 \\
$0.5 \mathrm{~mol}$ Toluene/0.5 mol Hexane (0.5: t-h) & -70.74 & -103.68 \\
$0.7 \mathrm{~mol}$ Toluene/ 0.3 mol Hexane (0.7: t-h) & -59.79 & -77.09 \\
Toluene & -104.73 & -126.10 \\
\hline
\end{tabular}

affinity by $\pi-\pi$ interactions (Goto et al., 2015), generating less adsorbate-adsorbent interaction, mainly with toluene.

Regarding to the samples, Figure 12 shows the immersion enthalpies of pure solvents and toluene-hexane mixtures in function of the molar fraction of toluene and the total acidity and basicity of samples. It can be seen that the immersion enthalpies increased with basicity and decrease with the total acidity of the samples, this occurred because according to other investigations the electron density of the adsorbent depended on its type of surface chemistry: electron withdrawing groups (like oxygen surface groups) reduced the adsorptive potential of the material whereas donating functional groups favored the electron density and then the adsorptive potential of the carbonaceous solid

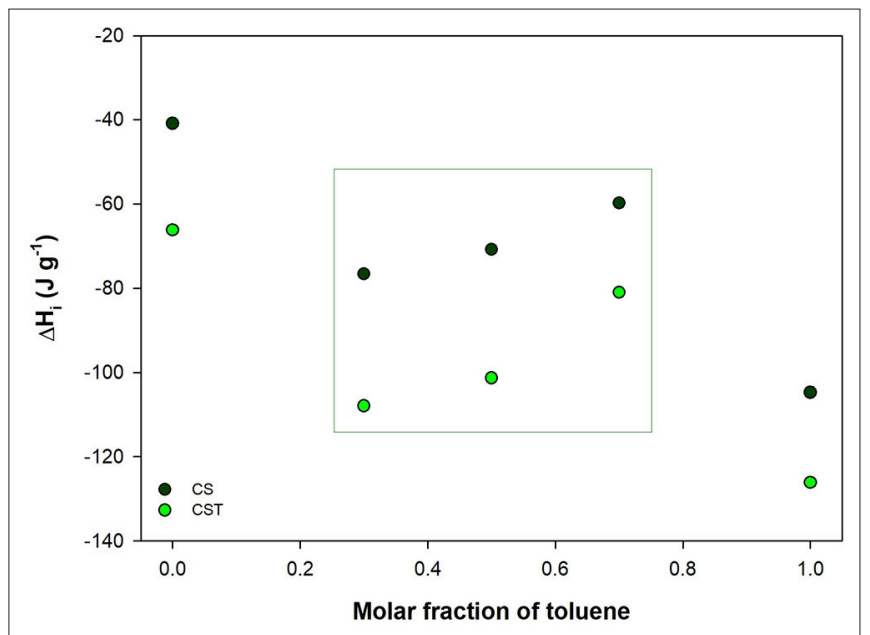

FIGURE 11 | Immersion enthalpies of pure solvents and toluene-hexane mixtures in function of the molar fraction of toluene in the mixture.

(Montes-Morán et al., 2012; Rubahamya et al., 2019). This is why enthalpies for CS were lower than for CST, since CS contained higher concentration of acidic oxygen groups, which reduced the electron density and the potential adsorptive of activated carbon, as well as the adsorption affinity by $\pi-\pi$ interactions (Goto et al., 2015), generating less adsorbate-adsorbent interaction, mainly with toluene; the opposite occurred with CST since when it was subjected to high temperature, electron withdrawing groups were removed and at the same time the concentration of aromatic rings in the solid structure was intensified (Contescu et al., 2018), increasing its electron density and therefore, the intensity of the interaction adsorbent-adsorbate was higher.

This figure also shows that the greatest adsorbent-adsorbate interaction occurred when there were fewer acid groups, greater presence of basic groups, and higher toluene content, while less energy was released when the sample contained higher content of acid groups, lower basicity and only hexane as adsorbate, showing that the extreme values of highest and lowest immersion enthalpy values corresponded to single-component systems (toluene or hexane as the only immersion liquid), this happened because when the starting sample was subjected to heat treatment, it was generated an unsaturated surface because of the desorption of acid-type functional groups, increasing the basicity, and at the same time, the lower content of oxygenated groups made the surface more akin to non-polar adsorbates as the studied hydrocarbons, but the interaction with toluene was higher since 

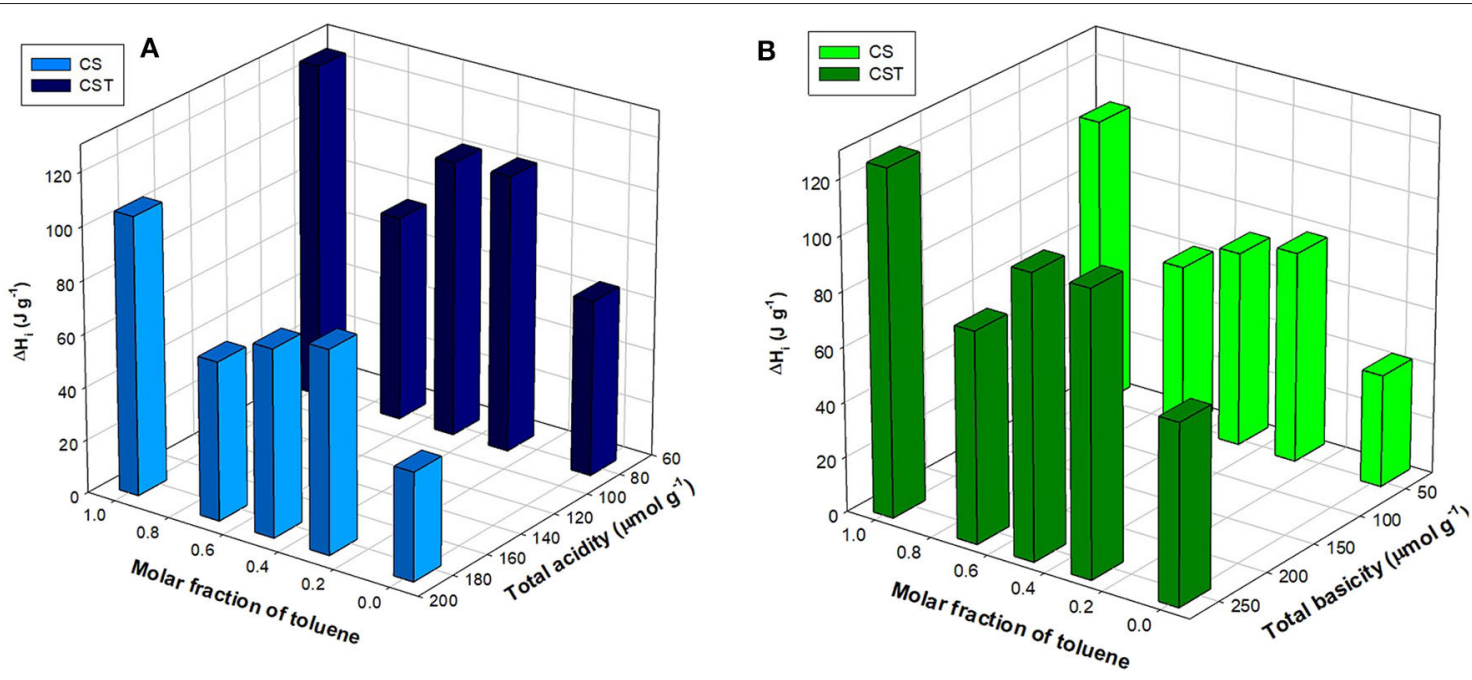

FIGURE 12 | Immersion enthalpies of pure solvents and toluene-hexane mixtures in function of the molar fraction of toluene and the total acidity (A) and basicity (B).

in addition to the aromatic ring generating $\pi-\pi$ interactions with the activated carbon (greater in CST because having a higher content of basicity increased the amount of $\pi \bar{e}$ available to interact with the adsorbate), $\mathrm{C}_{7} \mathrm{H}_{8}$ contained an electron-donor methyl group that increased the ring electronegativity, causing stronger attractions with the nucleophilic basal plane of the carbonaceous material (Daud and Houshamnd, 2010; Shafeeyan et al., 2010; Montes-Morán et al., 2012; Bhatnagar et al., 2013; Anuradha et al., 2014; Bedolla et al., 2014; Lo et al., 2014; da Costa Lopes et al., 2015; Abdulrasheed et al., 2018).

Whereas, if binary mixtures of these adsorbates were evaluated assuming that the process started with hexane as a pure component and different amounts of toluene were added, energetically more energy was released when the system was bicomponent regardless of the molar fraction, since the immersion enthalpies of the mixtures toluene-hexane at $0.3,0.5$, and 0.7 were higher than the immersion enthalpy of hexane as a pure solvent and this occurred in both samples because regardless of whether a displacement of hexane molecules by toluene molecules was occurring (as previously stated), between the solid and the binary mixture there was also another energetic contribution derived from the sum of the energy released by the toluene-surface interaction and the hexane-surface interaction, making the process more exothermic for the mixtures than for the aliphatic hydrocarbon as the only adsorbate.

Finally, comparing the adsorption processes from the gas and liquid phase, it was found that the amount adsorbed was greater in the gas phase because the particles in this phase (considered as ideal gases) did not present adsorptive-adsorptive interaction; while in the liquid phase there was not only adsorptive-adsorptive interaction (both for hexane and toluene) but also solute-solvent interaction, as well as a competition between the solute and the solvent to enter the porous structure, which made difficult the entrance of the adsorbate to the porous solid; on the other hand, the high hydrophobicity of toluene generated a high affinity with hexane, so that it hindered the adsorption of the aromatic compound (Goto et al., 2015). This was corroborated with the immersion enthalpies, because it was found that the energy released was greater when toluene was the immersion liquid (compared to hexane), but when toluene and hexane were together, it was seen that as toluene concentration increased, the immersion enthalpy of the mixture decreased, which probably occurred because there was displacement of hexane molecules by toluene molecules, which would require energy, causing the magnitude of the exothermic process to decrease (Unnikrishnan and Srinivas, 2016), showing that there is a competition for the adsorption sites.

\section{CONCLUSION}

Submitting the starting sample to thermal modification at $1173.15 \mathrm{~K}$ increased the textural parameters and the total basicity but decreased the total acidity, this caused the electron withdrawing groups to decrease and the electronic density of the solid to increase, favoring interactions with the adsorbates, mainly with toluene since it not only generated London forces but also $\pi-\pi$ interactions. When hexane was added as a solvent to the toluene adsorption process, the adsorption of the aromatic compound decreased because both molecules competed for the adsorption sites, and as the amount of $\mathrm{C}_{7} \mathrm{H}_{8}$ increased, a possible displacement of the hexane molecules was generated, making that the energy released decreased its magnitude because the displacement of a molecule of hexane by one of toluene required energy, leading to the adsorbed toluene amount was smaller for the liquid phase than for gas phase due to the fact that in the liquid phase there was not only adsorbent-adsorbate interaction, but also solute-solute, solute-solvent and solvent-solvent, added to the fact that the high affinity between toluene and hexane hindered the adsorption of the aromatic compound. 


\section{DATA AVAILABILITY STATEMENT}

The raw data supporting the conclusions of this article will be made available by the authors, without undue reservation.

\section{AUTHOR CONTRIBUTIONS}

The authors know the content of the paper and have contributed equally to each of its parts. All authors contributed to the article and approved the submitted version.

\section{REFERENCES}

Abd, A. A., Naji, S. Z., Hashim, A. S., and Othman, M. R. (2020). Carbon dioxide removal through physical adsorption using carbonaceous and noncarbonaceous adsorbents: a review. J. Environ. Chem. Eng. 2020:104142. doi: 10.1016/j.jece.2020.104142

Abdulrasheed, A. A., Jalil, A. A., Triwahyono, S., Zaini, M. A. A., Gambo, Y., and Ibrahim, M. (2018). Surface modification of activated carbon for adsorption of SO2 and NOX : a review of existing and emerging technologies. Renew. Sustain. Energy Rev. 94, 1067-1085. doi: 10.1016/j.rser.2018.07.011

Anuradha, S., Raj, K. J. A., Elangovan, T., and Viswanathan, B. (2014). Adsorption of VOC on steam activated carbon derived from coconut shell charcoal. Indian J. Chem. Technol. 21, 345-349. Available online at: http://nopr.niscair.res.in/ handle/123456789/32132

Assadi, Y., Ahmadi, F., and Hossieni, M. R. M. (2010). Determination of BTEX compounds by dispersive liquid-liquid microextraction with GC-FID. Chromatographia 71, 1137-1141. doi: 10.1365/s10337-010-1616-8

Bazzini, P., and Wermuth, C. G. (2015). "Substituent groups," in The Practice of Medicinal Chemistry. 4th Edn, eds C. G. Wermuth, D. Aldous, P. Raboisson, and D. Rognan (London: Elsevier), 319-357. doi: 10.1016/B978-0-12-417205-0.00013-4

Bedolla, P. O., Feldbauer, G., Wolloch, M., Eder, S. J., Dörr, N., Mohn, P., et al. (2014). Effects of van der Waals interactions in the adsorption of isooctane and ethanol on $\mathrm{Fe}(100)$ surfaces. J. Phys. Chem. C 118, 17608-17615. doi: $10.1021 /$ jp503829c

Bhatnagar, A., Hogland, W., Marques, M., and Sillanpää, M. (2013). An overview of the modification methods of activated carbon for its water treatment applications. Chem. Eng. J. 219, 499-511. doi: 10.1016/j.cej.2012. 12.038

Biniak, S., Pakuła, M., Swiatkowski, A., Bystrzejewski, M., and Błazewicz, S. (2010). Influence of high-temperature treatment of granular activated carbon on its structure and electrochemical behavior in aqueous electrolyte solution. J. Mater. Res. 25, 1617-1628. doi: 10.1557/JMR.2010.0207

Boehm, H. P. (1994). Some aspects of the surface chemistry of carbon blacks and other carbons. Carbon 32, 759-769. doi: 10.1016/0008-6223(94)90031-0

Cárdenas, H., and Müller, E. A. (2019). Molecular simulation of the adsorption and diffusion in cylindrical nanopores: effect of shape and fluid-solid interactions. Molecules 24:608. doi: 10.3390/molecules24030608

Chen, X. (2015). Modeling of experimental adsorption isotherm data. Information 6, 14-22. doi: 10.3390/info6010014

Chen, Z., Zhang, S., Liu, Y., Alharbi, N. S., Rabah, S. O., Wang, S., et al. (2020). Synthesis and fabrication of g-C3N4-based materials and their application in elimination of pollutants. Sci. Total Environ. 731:139054. doi: 10.1016/j.scitotenv.2020.139054

Cheng, D., Li, Z., Yan, J., and Jin, J. (2008). Adsorption behavior of pchlorophenol on the reed wetland soils. J. Environ. Sci. Technol. 1, 169-174. doi: $10.3923 /$ jest.2008.169.174

Cheng, Y., He, H., Yang, C., Zeng, G., Li, X., Chen, H., et al. (2016). Challenges and solutions for biofiltration of hydrophobic volatile organic compounds. Biotechnol. Adv. 34, 1091-1102. doi: 10.1016/j.biotechadv.2016.06.007

\section{ACKNOWLEDGMENTS}

The authors thank the Framework Agreement between the Universidad de los Andes and the Universidad Nacional de Colombia and the act of agreement established between the Chemistry Departments of the two universities. The authors also thank to the Colciencias Scholarship Doctorados Nacionales 2016 Convocation 757. The JM-P also appreciates the grant for the funding of research programs for Associate Professors, Full Professors, and Emeritus Professors announced by the Faculty of Sciences of the Universidad de Los Andes (Colombia), 01-202020, 20-01-2022, according to the project INV-2019-84-1786.

Contescu, C., Adhikari, S., Gallego, N., Evans, N., and Biss, B. (2018). Activated carbons derived from high-temperature pyrolysis of lignocellulosic biomass. C 4, 51-66. doi: 10.3390/c40 30051

da Costa Lopes, A. S., de Carvalho, S. M. L., do Socorro Barros Brasil, D., de Alcântara Mendes, R., and Lima, M. O. (2015). Surface modification of commercial activated carbon (cag) for the adsorption of benzene and toluene. Am. J. Anal. Chem. 6, 528-538. doi: 10.4236/ajac.2015. 66051

Daud, W. M. A. W., and Houshamnd, A. H. (2010). Textural characteristics, surface chemistry and oxidation of activated carbon. J. Nat. Gas Chem. 19, 267-279. doi: 10.1016/S1003-9953(09)60066-9

de Sá, A., Abreu, A. S., Moura, I., and Machado, A. V. (2017). "Polymeric materials for metal sorption from hydric resources," in Water Purification, ed A. M. Grumezescu (London: Academic Press, Inc.), 289-322. doi: 10.1016/B978-0-12-804300-4.00008-3

Denoyel, R., Rouquerol, F., and Rouquerol, J. (2014). "Porous texture and surface characterization from liquid - solid interactions: immersion calorimetry and adsorption from solution," in Adsorption by Powders and Porous Solids: Principles, Methodology and Applications, eds J. Rouquerol, F. Rouquerol, P. Llewellyn, G. Maurin, and K. S. W. Sing (Kidlington: Academic Press, Inc.), 273-300. doi: 10.1016/B978-008044464-2.50016-X

Diao, R., Zhang, H., Zhao, D., and Li, S. (2019). Adsorption and structure of benzene, toluene, and p-xylene in carbon slit pores: a Monte Carlo simulation study. Chem. Eng. Sci. 197, 120-134. doi: 10.1016/j.ces.2018.12.004

Dubinin, M. M. (1975). Physical Adsorption of Gases and Vapors in Micropores. Moscow: Academic Press, Inc. doi: 10.1016/B978-0-12-571809-7.50006-1

Dubinin, M. M. (1980). Water vapor adsorption and the microporous structures of carbonaceous adsorbents. Carbon N. Y. 18, 355-364. doi: 10.1016/0008-6223(80)90007-X

Figueiredo, J. L., Pereira, M. F. R., Freitas, M. M. A., and Órfão, J. J. M. (1999). Modification of the surface chemistry of activated carbons. Carbon N. Y. 37, 1379-1389. doi: 10.1016/S0008-6223(98)00333-9

Foo, K. Y., and Hameed, B. H. (2010). Insights into the modeling of adsorption isotherm systems. Chem. Eng. J. 156, 2-10. doi: 10.1016/j.cej.2009.09.013

Fu, X., Liu, Y., Deng, J., Jing, L., Zhang, X., Zhang, K., et al. (2020). Intermetallic compound PtMny-derived Pt-MnOx supported on mesoporous $\mathrm{CeO}_{2}$ : highly efficient catalysts for the combustion of toluene. Appl. Catal. A Gen. 595, 117509. doi: 10.1016/j.apcata.2020.117509

Giraldo, L., and Moreno-Piraján, J. C. (2007). "Instrumentación calorimétrica aplicada a la determinación de entalpias de inmersión de sólidos porosos," in Sólidos Porosos Preparación, Caracterización y Aplicaciones, ed J. C. MorenoPiraján (Bogotá: Ed. Uniandes), 281-297.

Giraldo, L., Rodríguez-Estupiñán, P., and Moreno-Piraján, J. C. (2018) "Calorimetry of immersion in the energetic characterization of porous solids," in Calorimetry - Design, Theory and Applications in Porous Solids, ed J. C. Moreno-Piraján (London: Intech Open Ltda), 35-53. doi: 10.5772/intechopen.71051

Golomeova, M., and Zendelska, A. (2016). “Application of some natural porous raw materials for removal of lead and zinc from aqueous solutions," in 
Microporous and Mesoporous Materials, ed R. S. Dariani (Rijeka: InTech), 87-102. doi: 10.5772/62347

Goto, T., Amano, Y., Machida, M., and Imazeki, F. (2015). Effect of polarity of activated carbon surface, solvent and adsorbate on adsorption of aromatic compounds from liquid phase. Chem. Pharm. Bull. 63, 726-730. doi: 10.1248/cpb.c15-00039

Guo, Y., Wen, M., Li, G., and An, T. (2020). Recent advances in VOC elimination by catalytic oxidation technology onto various nanoparticles catalysts: a critical review. Appl. Catal. B Environ. 2020:119447. doi: 10.1016/j.apcatb.2020.119447

Haghseresht, F., and Lu, G. Q. (1998). Adsorption characteristics of phenolic compounds onto coal-reject-derived adsorbents. Energy Fuels 12, 1100-1107. doi: $10.1021 /$ ef 9801165

He, K. Y., Wei, Q., Wang, Y. L., Wang, S., Cui, S. P., Li, Q. Y., et al. (2019). Hydrophobic mesoporous organosilica membranes: preparation and application in the separation of volatile organic compounds from water. Microporous Mesoporous Mater. 288:109606. doi: 10.1016/j.micromeso.2019.109606

Hernández-Monje, D., Giraldo, L., and Moreno-Piraján, J. C. (2019a). Immersion enthalpy of benzene/cyclohexane and toluene/cyclohexane binary mixtures into modified activated carbons. J. Therm. Anal. Calorim. 138, 2565-2575. doi: 10.1007/s10973-019-08478-0

Hernández-Monje, D., Giraldo, L., and Moreno-Piraján, J. C. (2019b). Interaction between hydrocarbons C6 and modified activated carbons: correlation between adsorption isotherms and immersion enthalpies. ACS Omega 4, 19595-19604. doi: 10.1021 /acsomega.9b02062

Hernández-Monje, D., Giraldo, L., and Moreno-Piraján, J. C. (2020a). Enthalpic characterization of activated carbons with different surface chemistry with organic solvents and water. J. Therm. Anal. Calorim. doi: 10.1007/s10973-020-09255-0

Hernández-Monje, D., Gutiérrez, L. G., and Moreno-Piraján, J. C, (2020b). Immersion enthalpy of activated carbons with different oxygen content in toluene-hexane mixtures. J. Mol. Liq. 310:113140. doi: 10.1016/j.molliq.2020.113140

Hofmann, T., Wallacher, D., Mayorova, M., Zorn, R., Frick, B., and Huber, P. (2012). Molecular dynamics of $n$-hexane: a quasi-elastic neutron scattering study on the bulk and spatially nanochannel-confined liquid. J. Chem. Phys. 136:124505. doi: $10.1063 / 1.3696684$

Hossein Tehrani, N. H. M., Alivand, M. S., Rashidi, A., Rahbar Shamskar, K., Samipoorgiri, M., Esrafili, M. D., et al. (2020). Preparation and characterization of a new waste-derived mesoporous carbon structure for ultrahigh adsorption of benzene and toluene at ambient conditions. J. Hazard. Mater. 384:121317. doi: 10.1016/j.jhazmat.2019.121317

Hu, B., Ai, Y., Jin, J., Hayat, T., Alsaedi, A., Zhuang, L., et al. (2020). Efficient elimination of organic and inorganic pollutants by biochar and biochar-based materials. Biochar 2, 47-64. doi: 10.1007/s42773-020-00044-4

Huang, Y., Steven, H., Lu, Y., Niu, R., Xu, L., and Cao, J. (2016). Removal of indoor volatile organic compounds via photocatalytic oxidation: a short review and prospect. Molecules 21, 56-76. doi: 10.3390/molecules21010056

Kamal, M. S., Razzak, S. A., and Hossain, M. M. (2016). Catalytic oxidation of volatile organic compounds (VOCs) - a review. Atmos. Environ. 140, 117-134. doi: 10.1016/j.atmosenv.2016.05.031

Kecili, R., and Hussain, C. M. (2018). "Mechanism of adsorption on nanomaterials," in Nanomaterials in Chromatography: Current Trends in Chromatographic Research Technology and Techniques, ed C. M. Hussain (Amsterdam: Elsevier), 89-115. doi: 10.1016/B978-0-12-812792-6.00004-2

Kim, Y. S., and Park, C. R. (2016). "Chapter 13 - titration method for the identification of surface functional groups," in Materials Science and Engineering of Carbon, ed M. Inagaki (Pekín: Tsinghua University Press Limited), 273-286. doi: 10.1016/B978-0-12-805256-3.00013-1

Klomkliang, N., Do, D. D., and Nicholson, D. (2012). Affinity and packing of benzene, toluene, and p-xylene adsorption on a graphitic surface and in pores. Ind. Eng. Chem. Res. 51, 5320-5329. doi: 10.1021/ie300121p

Lan, Y., Yang, Z., Wang, P., Yan, Y., Zhang, L., and Ran, J. (2019). A review of microscopic seepage mechanism for shale gas extracted by supercritical $\mathrm{CO}_{2}$ flooding. Fuel 238, 412-424. doi: 10.1016/j.fuel.2018.10.130

Laskar, I. I., and Hashisho, Z. (2020). Insights into modeling adsorption equilibria of single and multicomponent systems of organic and water vapors. Sep. Purif. Technol. 241, 116681-116703. doi: 10.1016/j.seppur.2020.116681
Lazzarini, A., Piovano, A., Pellegrini, R., Agostini, G., Rudić, S., Lamberti, C., et al. (2016). Graphitization of activated carbons: a molecular-level investigation by INS, DRIFT, XRD and raman techniques. Phys. Proc. 85, 20-26. doi: 10.1016/j.phpro.2016.11.076

Lee, H.-M., Kang, H.-R., An, K.-H., Kim, H.-G., and Kim, B.-J. (2013). Comparative studies of porous carbon nanofibers by various activation methods. Carbon Lett. 14, 180-185. doi: 10.5714/CL.2013.14.3.180

Lhuissier, M., Couvert, A., Amrane, A., Kane, A., and Audic, J. L. (2018). Characterization and selection of waste oils for the absorption and biodegradation of VOC of different hydrophobicities. Chem. Eng. Res. Des. 138, 482-489. doi: 10.1016/j.cherd.2018.08.028

Li, X., Zhang, L., Yang, Z., Wang, P., Yan, Y., and Ran, J. (2020). Adsorption materials for volatile organic compounds (VOCs) and the key factors for VOCs adsorption process: a review. Sep. Purif. Technol. 235:116213. doi: 10.1016/j.seppur.2019.116213

Liu, L., Luo, X. B., Ding, L., and Luo, S. L. (2019). "Application of nanotechnology in the removal of heavy metal from water," in Nanomaterials for the Removal of Pollutants and Resource Reutilization, eds X. B. Luo and F. Deng (London: Elsevier), 83-147. doi: 10.1016/B978-0-12-814837-2.00004-4

Liu, Q.-S., Zheng, T., Wang, P., Jiang, J.-P., and Li, N. (2010). Adsorption isotherm, kinetic and mechanism studies of some substituted phenols on activated carbon fibers. Chem. Eng. J. 157, 348-356. doi: 10.1016/j.cej.2009.11.013

Liu, R., Song, H., Li, B., Li, X., and Zhu, T. (2020). Simultaneous removal of toluene and styrene by non-thermal plasma-catalysis: effect of VOCs interaction and system configuration. Chemosphere 2020:127893. doi: $10.1016 /$ j.chemosphere.2020.127893

Lo, J., Velo-gala, I., and Sa, M. (2014). Surface modifications of activated carbon by gamma irradiation. Carbon N. Y. 67, 236-249. doi: 10.1016/j.carbon.2013.09.087

Mantri, R. V., Sanghvi, R., and Zhu, H. J. (2017). "Solubility of pharmaceutical solids," in Developing Solid Oral Dosage Forms: Pharmaceutical Theory and Practice, 2nd Edn, ed Y. Qiu (London: Academic Press, Inc.), 3-22. doi: 10.1016/B978-0-12-802447-8.00001-7

Martínez De Yuso, A., Izquierdo, M. T., Rubio, B., and Carrott, P. J. M. (2013). Adsorption of toluene and toluene-water vapor mixture on almond shell based activated carbons. Adsorption 19, 1137-1148. doi: 10.1007/s10450-013-9540-5

Mirzaei, A., Leonardi, S. G., and Neri, G. (2016). Detection of hazardous volatile organic compounds (VOCs) by metal oxide nanostructures-based gas sensors: a review. Ceram. Int. 42, 15119-15141. doi: 10.1016/j.ceramint.2016.06.145

Montes-Morán, M. A., Suárez, D., Angel Menéndez, J., and Fuente, E. (2012). “The basicity of carbons," in Novel Carbon Adsorbents, 1st Edn, ed J. M. D. Tascón (Oxford: Elsevier), 173-203. doi: 10.1016/B978-0-08-097744-7.00006-5

Moreno-Piraján, J. C., Giraldo, L., García-Cuello, V., Vargas Delgadillo, D. P., Rodríguez-Estupiñán, P., Murillo-Acevedo, Y., et al. (2011). "Thermodynamic of the interactions between gas-solid and solid-liquid on carbonaceous materials," in Thermodynamics - Interaction Studies - Solids, Liquids and Gases (London), 164-195.

Mu, T.-H., and Sun, H.-N. (2019). "Sweet potato leaf polyphenols: preparation, individual phenolic compound composition and antioxidant activity," in Polyphenols in Plants, ed R. R. Watson (London: Academic Press, Inc.), 365-380. doi: 10.1016/B978-0-12-813768-0.00022-0

Nguyen, T. X., and Bhatia, S. K. (2012). Characterization of accessible and inaccessible pores in microporous carbons by a combination of adsorption and small angle neutron scattering. Carbon N. Y. 50, 3045-3054. doi: 10.1016/j.carbon.2012.02.091

Nishio, M., Umezawa, Y., Honda, K., Tsuboyama, S., and Suezawa, H. (2009). $\mathrm{CH} / \pi$ hydrogen bonds in organic and organometallic chemistry. CrystEngComm 11, 1757-1788. doi: 10.1039/b902318f

Omri, A., and Benzina, M. (2012). Characterization of activated carbon prepared from a new raw lignocellulosic material: Ziziphus Spina-Christi seeds. J. la Société Chim. Tunisie 14, 175-183. Available online at: http://www.sctunisie. org/pdf/JSCT_v14-22.pdf

Rehman, A., Park, M., and Park, S. J. (2019). Current progress on the surface chemical modification of carbonaceous materials. Coatings 9, 103-124. doi: $10.3390 /$ coatings 9020103

Rodríguez, G., Giraldo, L., and Moreno-Piraján, J. C. (2007). Preparación de carbones activados a partir de materiales tejidos y caracterizacción estructural por adsorción y difracción de rayos x. Rev. Colomb. Quím. 36, 259-269. 
Available online at: https://revistas.unal.edu.co/index.php/rcolquim/article/ view/882/1710

Rubahamya, B., Kumar Reddy, K. S., Prabhu, A., Al Shoaibi, A., and Srinivasakannan, C. (2019). Porous carbon screening for benzene sorption. Environ. Prog. Sustain. Energy 38, 93-99. doi: 10.1002/ep.12925

Salar-García, M. J., Ortiz-Martínez, V. M., Hernández-Fernández, F. J., de los Ríos, A. P., and Quesada-Medina, J. (2017). Ionic liquid technology to recover volatile organic compounds (VOCs). J. Hazard. Mater. 321, 484-499. doi: 10.1016/j.jhazmat.2016.09.040

Shafeeyan, M. S., Mohd, W., Wan, A., Houshmand, A., and Shamiri, A. (2010). A review on surface modification of activated carbon for carbon dioxide adsorption. J. Anal. Appl. Pyroly. 89, 143-151. doi: 10.1016/j.jaap.2010.07.006

Sheshdeh, R. K., Abbasizadeh, S., Nikou, M. R. K., Badii, K., and Sharafi, M. S. (2014). Liquid Phase adsorption kinetics and equilibrium of toluene by novel modified-diatomite. J. Environ. Heal. Sci. Eng. 12, 148-161. doi: 10.1186/s40201-014-0148-9

Sing, K. S. W., Rouquerol, F., and Rouquerol, J. (2014). "Classical interpretation of physisorption isotherms at the gas -solid interface," in Adsorption by Powders and Porous Solids, 2nd Edn (Oxford: Elsevier), 159-189. doi: 10.1016/B978-0-08-097035-6.00005-X

Stoeckli, H. F., and Kraehenbuehl, F. (1981). The enthalpies of immersion of active carbons, in relation to the Dubinin theory for the volume filling of micropores. Carbon N. Y. 19, 353-356. doi: 10.1016/0008-6223(81)90059-2

Stoeckli, H. F., Kraehenbuehl, F., Ballerini, L., and de Bernardini, S. (1989). Recent developments in the Dubinin equation. Carbon N. Y. 27, 125-128. doi: 10.1016/0008-6223(89)90165-6

Stofela, S. K. F., de Almeida Neto, A. F., Gimenes, M. L., and Vieira, M. G. A. (2015). Adsorption of toluene into commercial organoclay in liquid phase: kinetics, equilibrium and thermodynamics. Can. J. Chem. Eng. 93, 998-1008. doi: $10.1002 /$ cjce. 22174

Tascón, J. M. D. (2007). Materiales de carbono: estructuras y formas. Opt. Pura Apl. 40, 149-159. Available online at: https://www.sedoptica.es/Menu_Volumenes/ Pdfs/252.pdf

Thommes, M., Kaneko, K., Neimark, A. V., Olivier, J. P., Rodriguez-Reinoso, F., Rouquerol, J., et al. (2015). Physisorption of gases, with special reference to the evaluation of surface area and pore size distribution (IUPAC Technical Report). Pure Appl. Chem. 87, 1051-1069. doi: 10.1515/pac-2014-1117

Thongsai, N., Jaiyong, P., Kladsomboon, S., In, I., and Paoprasert, P. (2019). Utilization of carbon dots from jackfruit for real-time sensing of acetone vapor and understanding the electronic and interfacial interactions using density functional theory. Appl. Surf. Sci. 487, 1233-1244. doi: 10.1016/j.apsusc.2019.04.269

Tomatis, M., Moreira, M. T., Xu, H., Deng, W., He, J., and Parvez, A. M. (2019). Removal of VOCs from waste gases using various thermal oxidizers: a comparative study based on life cycle assessment and cost analysis in China. J. Clean. Prod. 233, 808-818. doi: 10.1016/j.jclepro.2019.06.131

Unnikrishnan, P., and Srinivas, D. (2016). "Heterogeneous Catalysis," in Industrial Catalytic Processes for Fine and Specialty Chemicals, eds S. S. Joshi and V. V Ranade (London: Elsevier), 41-111. doi: 10.1016/B978-0-12-801457-8.00003-3

Venkatachalam, and Chavare, S. D. (2010). Development of gas chromatographic method for carcinogens. J. Chem. Pharm. Res. 2, 180-186. Available online at: https://www.jocpr.com/articles/development-of-gas-chromatographicmethod-for-carcinogens.pdf

Wang, D., McLaughlin, E., Pfeffer, R., and Lin, Y. S. (2011). Aqueous phase adsorption of toluene in a packed and fluidized bed of hydrophobic aerogels. Chem. Eng. J. 168, 1201-1208. doi: 10.1016/j.cej.2011. 02.014

Wang, G., Dou, B., Zhang, Z., Wang, J., Liu, H., and Hao, Z. (2015). Adsorption of benzene, cyclohexane and hexane on ordered mesoporous carbon. J. Environ. Sci. 30, 65-73. doi: 10.1016/j.jes.2014.10.015

Wang, H., Guo, H., Zhao, Y., Dong, X., and Gong, M. (2020). Thermodynamic analysis of a petroleum volatile organic compounds (VOCs) condensation recovery system combined with mixed-refrigerant refrigeration. Int. J. Refrig 116, 23-35. doi: 10.1016/j.ijrefrig.2020.03.011

Webster, C. E., Drago, R. S., Zerner, M. C., and Gaines, V. (1998). Molecular dimensions for adsorptives. J. Am. Chem. Soc. 120, 5509-5516. doi: $10.1021 /$ ja973906m

Yang, C., Miao, G., Pi, Y., Xia, Q., Wu, J., Li, Z., et al. (2019). Abatement of various types of VOCs by adsorption/catalytic oxidation: a review. Chem. Eng. J. 370, 1128-1153. doi: 10.1016/j.cej.2019.03.232

Zhang, X., Gao, B., Creamer, A. E., Cao, C., and Li, Y. (2017). Adsorption of VOCs onto engineered carbon materials: a review. J. Hazard. Mater. 338, 102-123. doi: 10.1016/j.jhazmat.2017.05.013

Zhou, J., Luo, A., and Zhao, Y. (2018). Preparation and characterisation of activated carbon from waste tea by physical activation using steam. J. Air Waste Manag. Assoc. 68, 1269-1277. doi: 10.1080/10962247.2018.1460282

Zhou, K., Ma, W., Zeng, Z., Ma, X., Xu, X., Guo, Y., et al. (2019). Experimental and DFT study on the adsorption of VOCs on activated carbon/metal oxides composites. Chem. Eng. J. 372, 1122-1133. doi: 10.1016/j.cej.2019.04.218

Zhou, L., Yu, Q., Cui, Y., Xie, F., Li, W., Li, Y., et al. (2017). Adsorption properties of activated carbon from reed with a high adsorption capacity. Ecol. Eng. 102, 443-450. doi: 10.1016/j.ecoleng.2017.02.036

Zhu, L., Shen, D., and Luo, K. H. (2020). A critical review on VOCs adsorption by different porous materials: Species, mechanisms and modification methods. J. Hazard. Mater. 389:122102. doi: 10.1016/j.jhazmat.2020. 122102

Živković, J. M., Stanković, I. M., Ninković, D. B., and Zarić, S. D. (2019). Phenol and toluene stacking interactions, including interactions at large horizontal displacements. study of crystal structures and calculation of potential energy surfaces. Cryst. Growth Des. 20, 1025-1034. doi: 10.1021/acs.cgd.9b01353

Conflict of Interest: The authors declare that the research was conducted in the absence of any commercial or financial relationships that could be construed as a potential conflict of interest.

Copyright (C) 2020 Hernández-Monje, Giraldo and Moreno-Piraján. This is an openaccess article distributed under the terms of the Creative Commons Attribution License (CC BY). The use, distribution or reproduction in other forums is permitted, provided the original author(s) and the copyright owner(s) are credited and that the original publication in this journal is cited, in accordance with accepted academic practice. No use, distribution or reproduction is permitted which does not comply with these terms. 